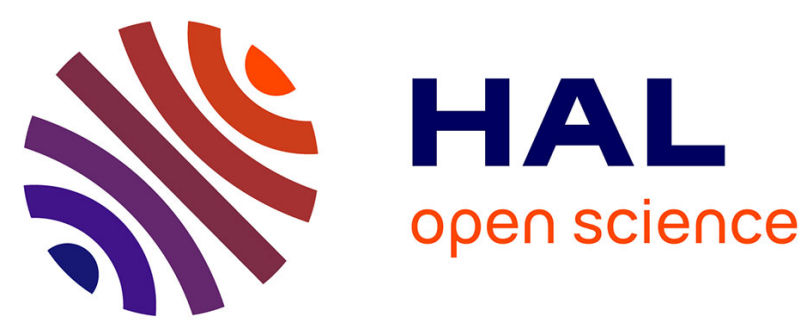

\title{
A Humins-Derived Magnetic Biochar for Water Purification by Adsorption and Magnetic Separation
}

\author{
C. Lomenech, Ch. Hurel, L. Messina, M. Schembri, P. Tosi, F. Orange, \\ Frédéric Georgi, Alice Mija, P. Kuzhir
}

\section{- To cite this version:}

C. Lomenech, Ch. Hurel, L. Messina, M. Schembri, P. Tosi, et al.. A Humins-Derived Magnetic Biochar for Water Purification by Adsorption and Magnetic Separation. Waste and Biomass Valorization, 2021, 12 (12), pp.6497-6512. 10.1007/s12649-021-01481-3 . hal-03280245

\section{HAL Id: hal-03280245 \\ https://hal.univ-cotedazur.fr/hal-03280245}

Submitted on 7 Jan 2022

HAL is a multi-disciplinary open access archive for the deposit and dissemination of scientific research documents, whether they are published or not. The documents may come from teaching and research institutions in France or abroad, or from public or private research centers.
L'archive ouverte pluridisciplinaire HAL, est destinée au dépôt et à la diffusion de documents scientifiques de niveau recherche, publiés ou non, émanant des établissements d'enseignement et de recherche français ou étrangers, des laboratoires publics ou privés. 


\title{
A humins-derived magnetic biochar for water purification by adsorption and magnetic separation
}

\author{
C. Lomenech ${ }^{1, *}$, Ch. Hurel ${ }^{1}$, L. Messina ${ }^{1}$, M. Schembri ${ }^{1}$, P. Tosi ${ }^{2}$, F. Orange ${ }^{3}$, F. Georgi ${ }^{4}$, A. \\ Mija $^{2}$, P. Kuzhir ${ }^{1}$. \\ ${ }^{1}$ Université Côte d'Azur, Institut de Physique de Nice, 06108 Nice, France \\ ${ }^{2}$ Université Côte d'Azur, Institut de Chimie de Nice, 06108 Nice, France \\ ${ }^{3}$ Université Côte d'Azur, Centre Commun de Microscopie Appliquée (CCMA), 06108 Nice, \\ France \\ ${ }^{4}$ MINES ParisTech, PSL University, CEMEF - Centre de mise en forme des matériaux, CNRS \\ UMR 7635, CS 10207 rue Claude Daunesse, 06904 Sophia-Antipolis Cedex, France \\ *corresponding author \\ e-mail address: claire.lomenech@univ-cotedazur.fr
}

\begin{abstract}
In this study, the use of magnetic biochar particles recovered from biorefinery by-products (humins) for adsorption of hydrophilic organic pollutants was investigated. The biochar was prepared by thermal treatment of crude humins followed by a grinding step after which a magnetic iron oxide was co-precipitated on the biochar surface. The resulting iron oxide content of the biochar composite was found to be $9 \%$ by volume, and the presence of a characteristic $\mathrm{Fe}-\mathrm{O}$ vibrational band was observed by FTIR-ATR. XPS analysis of Fe2p spectrum enabled the nature of iron oxide to be identified as maghemite. Finally, magnetometry measurements demonstrated the superparamagnetic properties of maghemite.

The adsorption of methylene blue on the biochar composite was found to be fast (less than 1 hour at $\mathrm{pH} 6$ with an initial concentration of methylene blue of $2 \cdot 10^{-5} \mathrm{~mol} . \mathrm{L}^{-1}$ ). Kinetics data were satisfactorily modelled by both first and second order models. Freundlich and Langmuir models were applied to adsorption isotherms data. Maximum adsorption capacity $\left(3.35 \cdot 10^{-5} \mathrm{~mol} . \mathrm{g}^{-1}\right)$, and Langmuir and Freundlich constants $\left(2.33 \cdot 10^{4} \mathrm{~L} \cdot \mathrm{mol}^{-1}\right.$ and $5.70 \cdot 10^{-5} \mathrm{~mol}^{0.913} \cdot \mathrm{L}^{0.087} \cdot \mathrm{g}^{-1}$ respectively) were found to be comparable to the average of those found in the literature. Electrostatic attraction between oppositely charged methylene blue and magnetic biochar was presumed to be the dominant interaction governing adsorption at environmental $\mathrm{pH}$ values. Lastly, a laboratory-scale experimental device with magnetic filtration under flow allowed the complete separation of the magnetic biochar composite from the liquid phase. This study shows that this magnetic biochar composite is a promising and economically interesting recovery route for biorefinery by-products and could be used for adsorption purposes.
\end{abstract}


Keywords: humins $\bullet$ magnetic biochar $\bullet$ water decontamination $\bullet$ magnetic separation $\bullet$ industrial by-product valorisation

\section{Graphical Abstract}

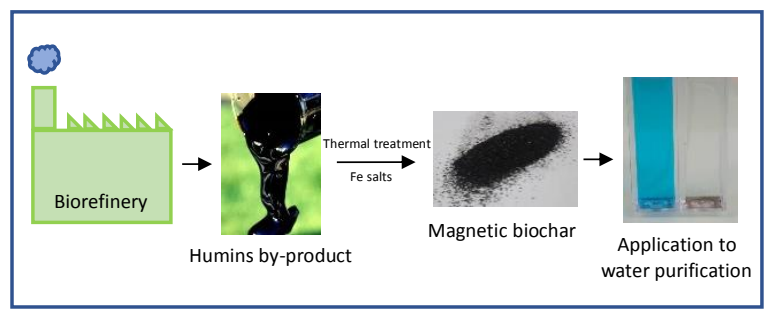

\section{Statement of Novelty}

In this work we focus on the valorization of biorefinery by-products with a "zero waste objective", by using them to produce a magnetic solid carbonaceous material that is able to remove organic hydrophilic pollutants from water. This is the first time such a study has been undertaken, the impetus for which is the very large volume of by-products that are produced as a consequence of biorefinery activity. Biorefinery by-products could be transformed into adsorbents of economic interest and could replace activated carbons, which are expensive to produce. Moreover, the magnetic properties of the carbonaceous material derived from biorefinery by-products allow it to be easily separated from decontaminated water after the pollutant has been trapped on its surface, without requiring filters.

\section{Introduction}

The "zero waste objective" is a new paradigm advocating that all discarded materials be designed to become resources for others. This approach aims to be ethical, economical, efficient, to guide people in changing their lifestyles and practices, and emulate sustainable cycles. Hence, a current challenge is to transform by-products (agricultural, industrial or domestic waste) into valuable materials with the objective to lower the waste accumulation and management issues, which are key challenges from an economic, environmental and sanitary point of view. Thermal degradation of domestic or agricultural biomass allows for the reduction of waste volumes. The resulting carbonaceous materials are called biochar and are of great interest since they present high performance, at low cost and with low environmental impacts, making them an alternative to the 
conventional carbonaceous materials (such as activated carbon, carbon nanotubes, graphene oxide). Recently, the use of biochar to remove organic pollutants and heavy metals has attracted much attention due to its interesting adsorption properties, low cost, and compliance with the "zero waste objective" paradigm [1-6]. Compared to activated carbons, biochars are prepared at lower temperatures, which significantly reduces energy consumption for their preparation, resulting in a lower effective cost and environmental impact [7-9].

However, due to the small particle sizes and low density, the separation step of the powdered biochar from the aqueous phase is a problem that requires centrifugation and/or filtration steps, limiting the large-scale use of biochar for wastewater treatment [10-13]. Moreover, a remobilisation of pollutants could occur during filtration and centrifugation [14]. To overcome these limitations, metal oxides have been introduced in the biochar matrix in order to produce a magnetic biochar and to separate it by simple application of a magnetic field [15]. Magnetic biochars are mainly synthesized via calcination, pyrolysis activation or chemical co-precipitation [16-18]. Co-precipitation has the advantages of shorter process times, simple reaction conditions and higher product purity. The calcination method is relatively simple and employs autoclave heating to produce magnetic biochar. In contrast, traditional heating methods require heavy mechanical systems and inert gas to create an inert atmosphere for magnetic biochar production [19]. Other methods such as ball-milling [20], molten salt [21], cross-linking of biochar and iron oxides [22], and microwave-assisted pyrolysis methods [23] have been proposed. Depending on the selected synthetic method used to obtain a magnetic biochar, the physico-chemical properties of magnetic biochar vary and the choice of the synthetic method should be decided by considering the nature of the raw biomass, the physicochemical properties of the pollutants and the method operability [14]. For example, Ruthiraan et al. [24] have synthesized a magnetic biochar from mangosteen peel and the resulting removal efficiencies of methylene blue from aqueous solutions were up to $46.3 \mathrm{mg} \cdot \mathrm{g}^{-1}$, without surface activation.

The adsorption efficiency of methylene blue is governed by several parameters such as $\mathrm{pH}$, initial concentration of methylene blue, contact time, adsorbent dosage, and the presence of competing ions. Of these parameters, $\mathrm{pH}$ is one of the key factors affecting adsorption. It has been shown that higher $\mathrm{pH}$ was more favorable for methylene blue adsorption on carbonaceous materials, and that the lower adsorption under acidic conditions could be due to the protonation of the acidic functional groups as well as the competition for adsorption sites between hydrogen ions and methylene blue $[25,26]$. 
According to previous studies, biochar has mainly been obtained from agriculture waste [27-29], municipal solid waste and food waste $[3,30,31]$. There are very few biochars stemming from industrial products or side-products, although some have been obtained from PVC plastics [32], or glue residues [33]. Of these industrial side-products, humins are produced by biorefineries. They are produced in large quantities and represent the major fraction of biorefinery side-products generated during chemocatalytic polysaccharide conversion [34]. Biorefineries are involved in green chemistry and the conversion from linear economy to circular economy by reusing or recycling side-products since (i) biomass conversion is a promising green alternative to the exploitation of fossil resources and (ii) each side product is intended to be converted into a high added-value bio-based product. The main valorization routes of humins have been energy and heat production (burning and gasification [35]), but recently they have been used as a matrix to produce composites and thermoset materials, thus expanding the scope of humins usage as bio-based building materials [36]. Tosi et al. [37,38] recently proposed a simple thermal treatment applied to crude humins to produce crosslinked rigid foams with controlled morphology, porosity and carbon content that could be used for environmental purposes, for example, in the replacement of expensive activated carbon.

The objective of this work was to use a magnetic biochar starting from humins, for the first time, as an adsorbent for methylene blue removal from wastewater. Humins first underwent a thermal treatment previously proposed by Tosi et al. [37] in order to get a crosslinked rigid foam. Then, magnetic biochar was obtained by chemical co-precipitation under alkaline conditions [39]. After that, adsorption kinetics and adsorption isotherms were performed by using methylene blue as a pollutant. Finally, a magnetic separation protocol was designed, highlighting the optimal conditions for effective separation.

\section{Materials and Methods}

Humins - Crude humins were provided by Avantium Chemicals (Amsterdam), and produced during the industrial acid catalysed dehydration (ACD) of fructose into 5-methoxymethyl furfural (MMF). MMF is the key intermediate in the production of 2,5-furandicarboxylic acid, necessary for the production of the bioderived plastic polyethylene-furanoate (PEF). Prior to their utilization, the humins were distilled under high vacuum to remove the main fractions of HMF (hydroxymethyl furfural) and MMF, which are residual from the biorefinery processing. 
Preparation of non-magnetic biochar - $10 \mathrm{~g}$ of crude humins were placed in a nickel crucible, and foamed at $250{ }^{\circ} \mathrm{C}$ for 1 hour in a Nabertherm K430/75 air ventilated oven. Around $8 \mathrm{~g}$ of humins foams were obtained (mass loss $20 \%$ ), with an elemental carbon content of $63 \%$. The foaming protocol, mechanism and characterization are described in detail in a previous study [38]. These rigid humins foams were then crushed and finely milled to produce non-magnetic biochar particles.

Preparation of magnetic biochar - Magnetic biochar was obtained by coprecipitation of $\mathrm{Fe}(\mathrm{II})$ and $\mathrm{Fe}(\mathrm{III})$ ions on the particles of previously prepared non-magnetic biochar, in alkali medium, following an experimental procedure similar to that proposed by Karunanayake et al. [39].

$1.8 \mathrm{~g}$ of iron (III) chloride (Sigma-Aldrich, >97\%) were dissolved in $130 \mathrm{~mL}$ of ultrapure water and stirred at $60{ }^{\circ} \mathrm{C}$. In parallel, $3.66 \mathrm{~g}$ of iron(II) sulphate heptahydrate (Sigma-Aldrich, >99\%) were dissolved in $15 \mathrm{~mL}$ of ultrapure water at room temperature. After complete dissolution, the two solutions were mixed together and stirred at $60{ }^{\circ} \mathrm{C}$ for 5 minutes. A suspension of $5 \mathrm{~g}$ of nonmagnetic biochar in $50 \mathrm{~mL}$ of ultrapure water was then added to the mixture and stirred for 30 minutes at room temperature. An aqueous solution of sodium hydroxide $\left(10 \mathrm{~mol} . \mathrm{L}^{-1}\right.$, prepared from VWR AnalaR Normapur $\mathrm{NaOH}$ pellets, $>99 \%$ ) was then used to adjust the $\mathrm{pH}$ to $\sim 12$, in order to precipitate the magnetic iron oxide nanoparticles on the non-magnetic biochar surface. The black suspension was continuously stirred for $1 \mathrm{~h}$, followed by a decanting time of $24 \mathrm{~h}$. The solid fraction was then separated by Buchner filtration, washed three times with ultrapure water and once with ethanol. The magnetic biochar particles were dried in an oven at $50{ }^{\circ} \mathrm{C}$ for $48 \mathrm{~h}$, finally resulting in $5.39 \mathrm{~g}$ product. These particles were then further ground for the adsorption and magnetic separation studies.

Quantitative analysis of iron in the magnetic biochar - Quantitative analysis of the iron content in the magnetic biochar was performed by the inductive coupled plasma atomic emission spectroscopy (ICP-AES) with an OPTIMA 2000 apparatus from Perkin-Elmer, after dissolution of iron oxide nanoparticles associated with non-magnetic biochar, in concentrated hydrochloric acid (37\%, ACS Reagent, Sigma Aldrich) ( 0.2 g of magnetic biochar with $3 \mathrm{~mL}$ of $\mathrm{HCl}$, stirred until the supernatant became a stable yellow colour, which indicates the presence of iron in solution). Size distribution - Size distribution was determined by using a vibratory sieve shaker (Fritsch Analysette, Germany), with sieves ranging from $25 \mu \mathrm{m}$ to $400 \mu \mathrm{m}$.

Pycnometry - The volumetric mass density of the magnetic biochar particles $\left(\rho_{\text {part }}\right)$ was determined using a glass pycnometer by introducing a known mass, $m_{\text {part }}$, of magnetic biochar 
particles into the pycnometer and adding sufficient ultrapure water to completely fill the pycnometer. It was calculated using the following formula:

$\rho_{\text {part }}=\frac{m_{\text {part }}}{V_{\text {tot }}-\frac{m_{\text {tot }}-m_{\text {part }}}{\rho_{\text {water }}}}$

where $V_{\text {tot }}$ and $m_{\text {tot }}$ correspond respectively to the total volume of the glass flask and to the total mass of the suspension of particles, while the volumetric mass density of water $\left(\rho_{\text {water }}\right)$ was approximated to $1 \mathrm{~g} . \mathrm{cm}^{-3}$.

Vibrating Sample Magnetometry (VSM) - Magnetization curves of a dried powder of magnetic biochar were obtained by vibrating sample magnetometry on a VSM 4500 instrument from EG\&G Princeton Applied Research. The VSM produces an electric current (up to a 9 A maximum) supplying a pair of coaxial coils equipped with iron yokes, leading to a controlled magnetic field. The sample is placed between the coils, and is subjected to a magnetic field of increasing intensity until magnetic saturation. Experimental magnetization curves were fitted by the Langevin magnetization law, relevant for magnetic composites based on iron oxide nanoparticles [40]:

$$
M=M_{S}\left[\operatorname{coth}\left(\frac{\mu_{0} \mu_{p} H}{k T}\right)-\frac{k T}{\mu_{0} \mu_{p} H}\right]
$$

where $M$ is biochar magnetization and $M_{S}\left(\mathrm{~A} . \mathrm{m}^{-1}\right)$ is saturation magnetization of the magnetic biochar composite, $H$ is the intensity of the applied magnetic field $\left(\mathrm{A} \cdot \mathrm{m}^{-1}\right), \mu_{0}=4 \pi \cdot 10^{-7} \mathrm{H} \cdot \mathrm{m}^{-1}$ is the magnetic permeability of vacuum, $\mu_{p}=M_{p} V_{p}$ (A. $\left.\mathrm{m}^{2}\right)$ is the magnetic moment of iron oxide nanoparticles present inside the magnetic biochar composite, $M_{p}\left(\mathrm{~A} \cdot \mathrm{m}^{-1}\right)$ is saturation magnetization of iron oxide nanoparticles, and $V_{p}=\frac{\pi d^{3}}{6}\left(\mathrm{~m}^{3}\right)$ is their volume, while $d(\mathrm{~m})$ is the mean diameter of iron oxide nanoparticles, $k=1.38 \cdot 10^{-23} \mathrm{~J} . \mathrm{K}^{-1}$ is the Boltzmann constant, and $T \approx$ $298 \mathrm{~K}$ is the absolute temperature of the suspension. The two parameters for the fit of the experimental magnetization curves are the saturation magnetization $M_{S}$ of the magnetic biochar and the magnetic moment $\mu_{p}$ of the constitutive iron oxide nanoparticles. The first fitting parameter $\left(M_{S}\right)$ allows to evaluate the saturation magnetization of the iron oxide nanoparticles, $M_{P}$, as the ratio of the saturation magnetization, $M_{S}$, of the magnetic biochar composite to the iron oxide nanoparticle volume fraction $\phi$, calculated using the volumetric mass density determined by pycnometry and the quantity of iron oxide determined by ICP-AES. The second fitting parameter $\left(\mu_{\mathrm{p}}\right)$ allows for the evaluation of the diameter $d$ of iron oxide nanoparticles inside the magnetic biochar composite. 
Fourier Transform Infrared Spectroscopy (FTIR-ATR) - FTIR-ATR acquisitions were performed between $4000-500 \mathrm{~cm}^{-1}$ (resolution: $4 \mathrm{~cm}^{-1}$, 32 scans) using a Perkin Elmer IR apparatus using an Attenuated Total Reflectance (ATR) modulus with a zinc selenide crystal.

X-ray diffraction - XRD data were recorded at room temperature with a PANalyticalX'Pert PRO (MPD) using the Bragg-Brentano system $/ \lambda \mathrm{CuK}_{\alpha}\left(2 \theta\right.$ from 6 to $\left.70^{\circ}\right)$.

X-ray photoelectron spectroscopy - The XPS analyses were performed using a Thermo Scientific K-Alpha spectrometer equipped with an AlK $\alpha$ monochromated source $(400 \mu \mathrm{m}, 12000 \mathrm{~V}, 6 \mathrm{~mA}$, $1484.6 \mathrm{eV})$ and a low energy flood-gun for charge compensation (0.6 V, $100 \mu \mathrm{A})$. Survey scans were made with a pass energy of $200 \mathrm{eV}$ - step $1 \mathrm{eV}$; dwell time $20 \mathrm{~ms}$; 4 scans. High resolution scans were made with a pass energy $40 \mathrm{eV}$ - step $0.1 \mathrm{eV}$; dwell time $50 \mathrm{~ms} ; 8$ scans for standard analysis and 64 scans for Fe2p. The ellipsoid spot size is $400 \mu \mathrm{m}$ x $800 \mu \mathrm{m}$. The Thermo Avantage v5.959 software was used for data analysis. The spectra were calibrated by setting the C-C component of the $\mathrm{C} 1 \mathrm{~s}$ peak at $284.8 \mathrm{eV}$.

Scanning Electron Microscopy (SEM) and Energy-Dispersive X-ray spectroscopy (EDX) SEM and EDX analysis were performed using a Tescan Vega 3 XMU SEM X-Max ${ }^{\mathrm{N}} 50$ EDX detector (Oxford Instruments). Prior to observation, the magnetic biochar samples were mounted on a SEM stub and coated with platinum $(3 \mathrm{~nm})$.

Electrophoretic mobility measurements - Electrophoretic mobility measurements of magnetic biochar particles were carried out by LASER Doppler velocimetry using a ZetaSizer Nano-ZS apparatus (Malvern Instruments) equipped with a $532 \mathrm{~nm}$ LASER, in a thermostated sample holder $\left(25^{\circ} \mathrm{C}\right)$, and detection of the scattered light was performed at an angle of $17^{\circ}$ from the incident beam direction.

Suspensions of magnetic biochar were prepared at different $\mathrm{pH}$ values, then the zeta potential was deduced from electrophoretic mobility using the Henry equation and Smoluchowski approximation.

Methylene blue adsorption experiments - Adsorption of methylene blue ( $\geq 98 \%$, RAL Reagents) was studied as a function of methylene blue concentration and contact time for two $\mathrm{pH}$ values (2 and 6). The initial concentrations ranged from $2 \cdot 10^{-5}$ to $2 \cdot 10^{-3} \mathrm{~mol} . \mathrm{L}^{-1}$, whereas contact times ranged from 15 min to 8 days. Potassium chloride was chosen as a background electrolyte to ensure a constant ionic strength in solution. Experiments were carried at room temperature $\left(23 \pm 2{ }^{\circ} \mathrm{C}\right)$.

Experiments were conducted by mixing $0.1 \mathrm{~g}$ of magnetic biochar with $20 \mathrm{~mL}$ of a methylene blue solution in potassium chloride $\left(0.1 \mathrm{~mol} . \mathrm{L}^{-1}\right.$ solution, prepared from $\mathrm{KCl}$ Prolabo, Rectapur, >99\%) 
in a closed reactor. $\mathrm{pH}$ values were adjusted using dilute solutions $\left(0.1\right.$ and $\left.0.01 \mathrm{~mol} . \mathrm{L}^{-1}\right)$ of hydrochloric acid (37\%, ACS Reagent, Sigma Aldrich) and potassium hydroxide (>86\%, Prolabo, Normapur, Analytical reagent). The samples were then stirred on a rotating shaker with a speed of $40 \mathrm{rpm}$ and $\mathrm{pH}$ values were periodically adjusted. After stirring, the supernatant was separated from the magnetic biochar particles with a ferrite magnet. For kinetics experiments, the supernatant was periodically separated from the solid during the experiment. The concentration of methylene blue left in the supernatant was then measured by spectrophotometry using a Shimadzu UV-1800 double-beam UV-visible spectrophotometer. The absorbance was measured at $658 \mathrm{~nm}$, after dilution of the supernatant if necessary, and concentration of methylene blue in the supernatant was determined after a calibration curve with at least 4 methylene blue samples in 0.1 mol.L ${ }^{-1}$ potassium chloride in the range $2.5 \cdot 10^{-6}-2 \cdot 10^{-5} \mathrm{~mol}^{-1} \mathrm{~L}^{-1}$

The concentration of adsorbed methylene blue was calculated using the equation:

$\mathrm{q}_{\mathrm{t}}=\frac{\left(\mathrm{C}_{\mathrm{i}}-\mathrm{C}_{\mathrm{t}}\right) \times \mathrm{V}}{\mathrm{m}}$

where $q_{t}$ is the concentration of methylene blue adsorbed on the magnetic biochar at time $t$ (mol.g ${ }^{-1}$ of magnetic biochar ), $C_{i}$ and $C_{t}$ are the initial concentration and the concentration at time $\mathrm{t}$ of methylene blue in solution (mol. $\left.\mathrm{L}^{-1}\right), V$ is the volume of solution (L) and $m$ is the mass of magnetic biochar in the suspension $(\mathrm{g})$.

Modelling of the adsorption kinetics - Modelling of the kinetic data was performed using either the pseudo-first order model [41] or the pseudo-second order model [42, 43]. A non-linear form of the kinetic equation was preferred for the modelling [44, 45]:

-for the pseudo-first order model,

$q_{t}=q_{e}\left(1-e^{-k_{1} t}\right)$

-and for the pseudo-second order model,

$q_{t}=\frac{k_{2} q_{e}^{2} t}{1+k_{2} q_{e} t}$

where $q_{t}$ and $q_{e}$ are the quantities of adsorbed methylene blue in moles per gram of magnetic biochar, respectively at time $t$ and at equilibrium, and $k_{1}$ and $k_{2}$ are the pseudo-first order and pseudo-second order rate constants, respectively. It was shown that for the three kinetic experiments, nearly $100 \%$ methylene blue was adsorbed for the longest contact times; the corresponding equilibrium value $\left(q_{e}\right)$ was thus calculated and fixed during the modelling of the data. 
Modelling of the adsorption isotherm - Modelling of the isotherm data was performed using either the Langmuir model [46] or the Freundlich model [47], which lead to the following expressions:

$q_{e}=\frac{q_{\max } K_{L} C_{e}}{1+K_{L} C_{e}} \quad$ (Langmuir model)

$q_{e}=K_{F} C_{e}^{n} \quad$ (Freundlich model)

where $q_{e}$ is the quantity of adsorbed methylene blue at equilibrium, in mole per gram of magnetic biochar, $C_{e}$ is the equilibrium concentration of methylene blue in the solution (mol.L $\left.\mathrm{L}^{-1}\right), q_{\max }$ is the Langmuir maximum adsorption capacity $\left(\mathrm{mol} \cdot \mathrm{g}^{-1}\right), K_{L}$ is the Langmuir equilibrium constant $\left(\mathrm{L}^{\mathrm{mol}}{ }^{-1}\right), \mathrm{n}$ is the Freundlich non-linearity constant and $K_{F}$ is the Freundlich affinity coefficient $\left(\mathrm{mol}^{1-\mathrm{n}} \cdot \mathrm{L}^{\mathrm{n}} \cdot \mathrm{g}^{-1}\right)$.

Linearized expressions of the two models were used to model experimental data:

$\frac{1}{q_{e}}=\frac{1}{q_{\max }}+\frac{1}{q_{\max } K_{L}} \times \frac{1}{C_{e}} \quad$ (Langmuir model)

$\ln \left(q_{e}\right)=\ln \left(K_{F}\right)+n \ln \left(C_{e}\right) \quad$ (Freundlich model)

Magnetic separation setup and determination of the critical magnetic field - Magnetic separation of the magnetic biochar samples was studied using an experimental device made from a HARVARD Apparatus PHD 4400 syringe pump, which controlled the flow rate, connected with a TERUMO syringe (internal diameter $16.02 \mathrm{~mm}$, capacity $10 \mathrm{~mL}$ ) attached to a plastic tube (internal diameter $3.6 \mathrm{~mm}$ ) (Fig. 1). The filter was made from a nickel wire (diameter $0.25 \mathrm{~mm}$ ) twisted into a relatively dense plug inserted into the tube and placed in an electromagnet connected to a DC power supply delivering an electrical current between 0-5 A corresponding to the magnetic field intensity range $0-75 \mathrm{kA} \cdot \mathrm{m}^{-1}$. 


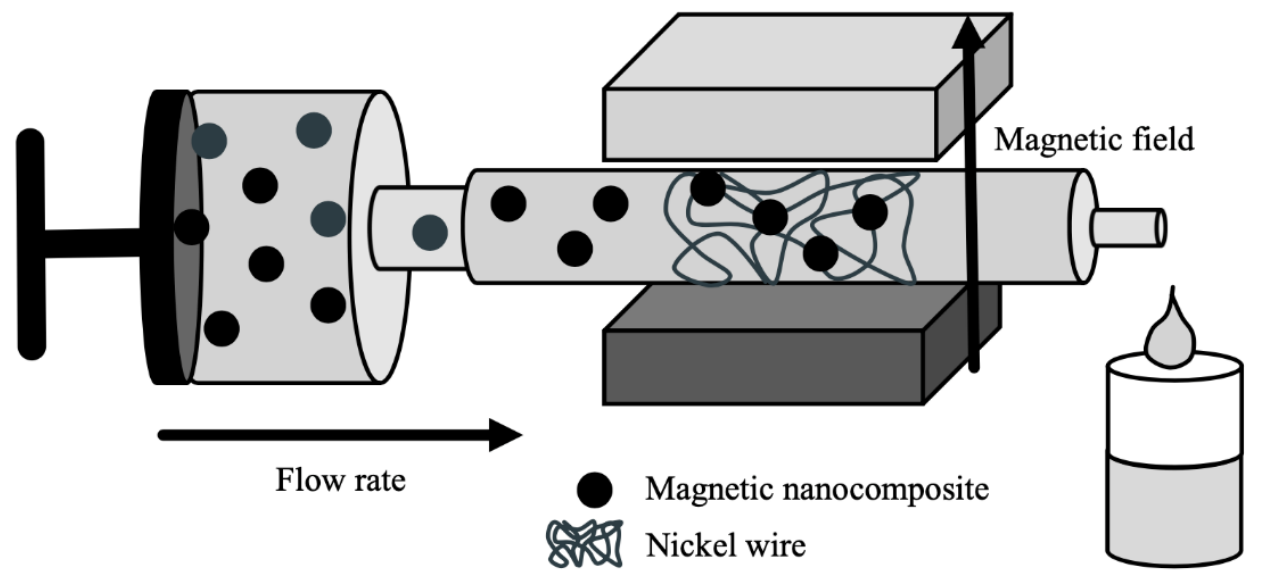

Fig. 1 Experimental device for the magnetic separation of humins-derived magnetic biochar particles

The critical magnetic field $\left(H_{\mathrm{c}}\right)$, corresponding to the minimal magnetic field to be applied for a given flow rate in order to remove most of the magnetic biochar particles, was firstly determined as follows: $0.3 \mathrm{~g}$ of magnetic biochar was added to $50 \mathrm{~mL}$ of water. The suspension was subjected to ultrasonication for 5 minutes (Bioblock Scientific Vibracell 75041, intensity 20\%) to break up the aggregates and limit the magnetic biochar particle sedimentation during the magnetic separation experiment. Then, the suspension was placed into the syringe and pushed through the channel containing a nickel wire. A series of flow rates were tested $\left(0.25,0.5,0.75\right.$ and $\left.1 \mathrm{~mL} . \mathrm{min}^{-1}\right)$. For each flow rate value, the magnetic field intensity delivered to the electromagnet was varied between 0 and $\sim 75 \mathrm{kA} \cdot \mathrm{m}^{-1}$. After passing through the electromagnet, the aqueous sample was collected in a plastic container. To check the presence of remaining magnetic biochar particles, a neodymium magnet was placed under the container. It allowed accumulation of magnetic biochar particles on the bottom of the container and the presence of these particles was checked using a magnifying glass with a magnification factor of 1.5. The critical value of the magnetic field corresponds to the lowest magnetic field intensity value at a given flow rate for which no particle is detected after magnetic separation.

Adsorption combined with magnetic separation - Experiments were performed in two steps: first methylene blue was adsorbed on the magnetic biochar, second, suspensions of magnetic biochar covered with methylene blue were passed through the magnetic separation device with a $0.5 \mathrm{~mL} . \mathrm{min}^{-1}$ flow rate and a magnetic field of $70 \mathrm{kA} . \mathrm{m}^{-1}$ (these conditions were deduced from 
determination of the critical magnetic field $H_{c}$ ). For the first step of this experiment, $0.107 \mathrm{~g}$ of magnetic biochar was added to $20 \mathrm{~mL}$ of methylene blue solution with a concentration of $10 \mathrm{mg}$. $\mathrm{L}^{-}$ ${ }^{1}\left(3.13 \cdot 10^{-5}\right.$ mol.L $\left.{ }^{-1}\right)$. The suspension was stirred for $12 \mathrm{~h}$ with a rotator stirrer. For the second step of the experiment, $10 \mathrm{~mL}$ of the magnetic biochar/methylene blue suspension were inserted into the syringe and were pushed through a magnetic separator (Fig. 1) subjected to an external magnetic field. The collected solution at the exit of the magnetic separator was analysed with UVvisible spectrophotometry. In order to check any effect of ultrasonication on the adsorption equilibrium, experiments were done with and without ultrasonication. 


\section{Results and discussion}

\section{Characterization of the magnetic biochar particles}

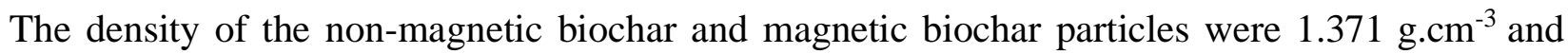
$1.792{\mathrm{~g} . \mathrm{cm}^{-3}}$, respectively. The magnetic biochar had a higher density than the non-magnetic biochar. Considering that the density of the iron oxides is around $\rho_{p} \sim 4.8-5.2 \mathrm{~g} . \mathrm{cm}^{-3}$, it can be assumed that the higher density of magnetic biochar is associated to the presence of the magnetic nanoparticles in the magnetic biochar. The volume $(\Phi=11-12$ vol.\% $)$ and weight $\left(\Phi_{\mathrm{w}}=32-33\right.$ wt.\%.) fractions of iron oxide nanoparticles that are incorporated into magnetic biochar composite, were determined from the density values of both non-magnetic biochar and magnetic biochar. The particle concentration obtained with ICP-AES method appeared to be somewhat lower: $\Phi \approx 9$ vol. $\%$ and $\Phi_{\mathrm{w}} \approx 25$ wt. $\%$.

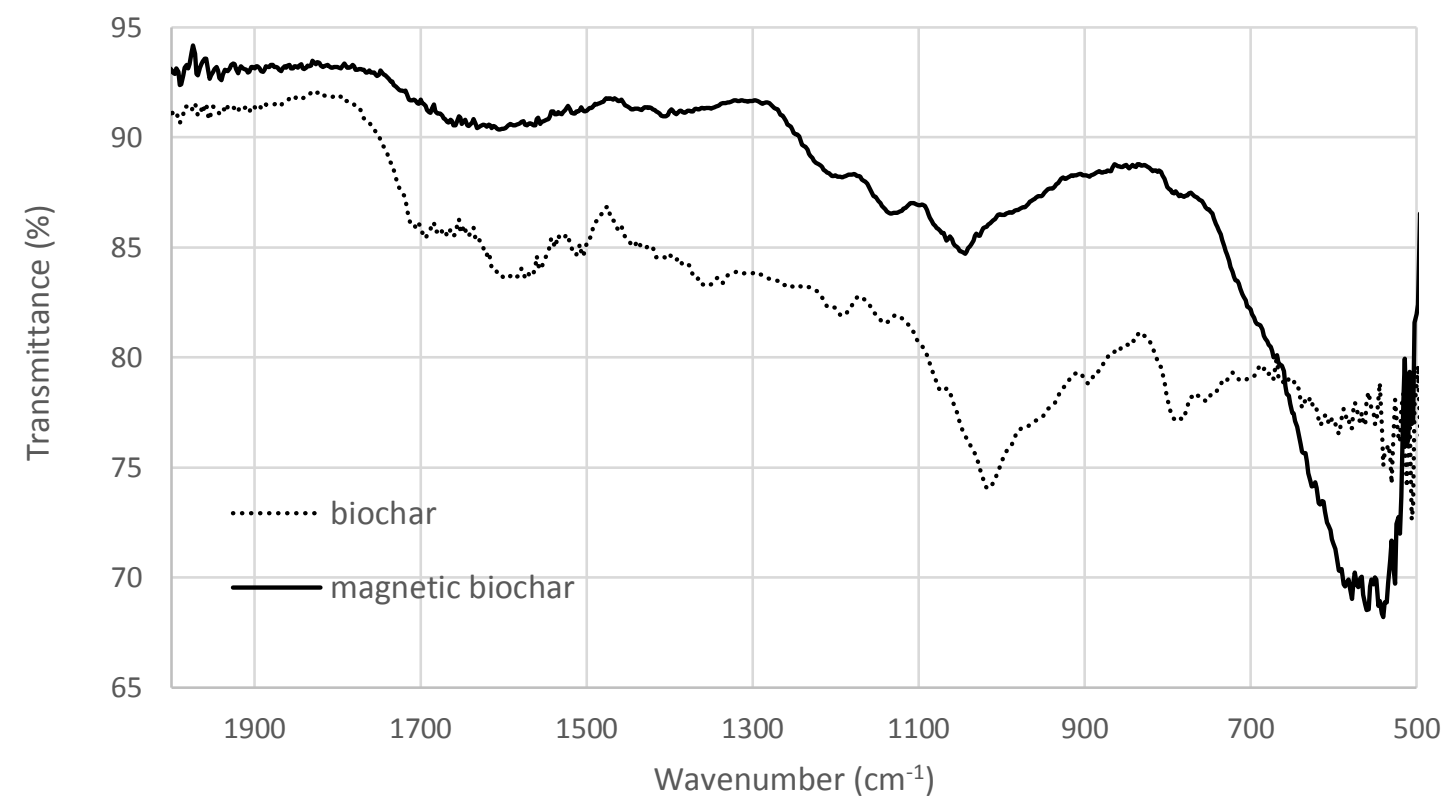

Fig. 2 FTIR-ATR spectra of non-magnetic biochar and magnetic biochar

ATR-IR spectra were obtained for biochar and magnetic biochar (Fig. 2). The FTIR-ATR spectra of magnetic biochar revealed broad and strong vibrational bands in the $530-580 \mathrm{~cm}^{-1}$ range, which are characteristic of the Fe-O bond in magnetic iron oxides [48, 49], thus confirming that iron oxide precipitation occurred on the biochar surface. From 2000 to $1000 \mathrm{~cm}^{-1}$, IR spectra of biochar and magnetic biochar both exhibit peaks usually ascribed to different motions of the oxygenated groups 
(C-O, C-O-H, C-O-C) $\quad\left(1000-1400 \mathrm{~cm}^{-1}\right)$ and stretching of $(\mathrm{C}=\mathrm{O}$ and $\mathrm{C}=\mathrm{C})$ groups $(1600-1800$ $\mathrm{cm}^{-1}$ ), usually observed in carbon materials [50]. Previous studies have demonstrated that, for the present non-magnetic biochar sample, the main chemical groups were lactone, carboxyl, hydroxyl and aromatic $[37,38]$.

The XRD diagram of magnetic biochar is shown on Fig. 3. The position and intensity of the peaks were similar to card PDF2 ICCD n 96-900-6317 (maghemite) and card PDF2 ICCD n 96-9005840 (magnetite).

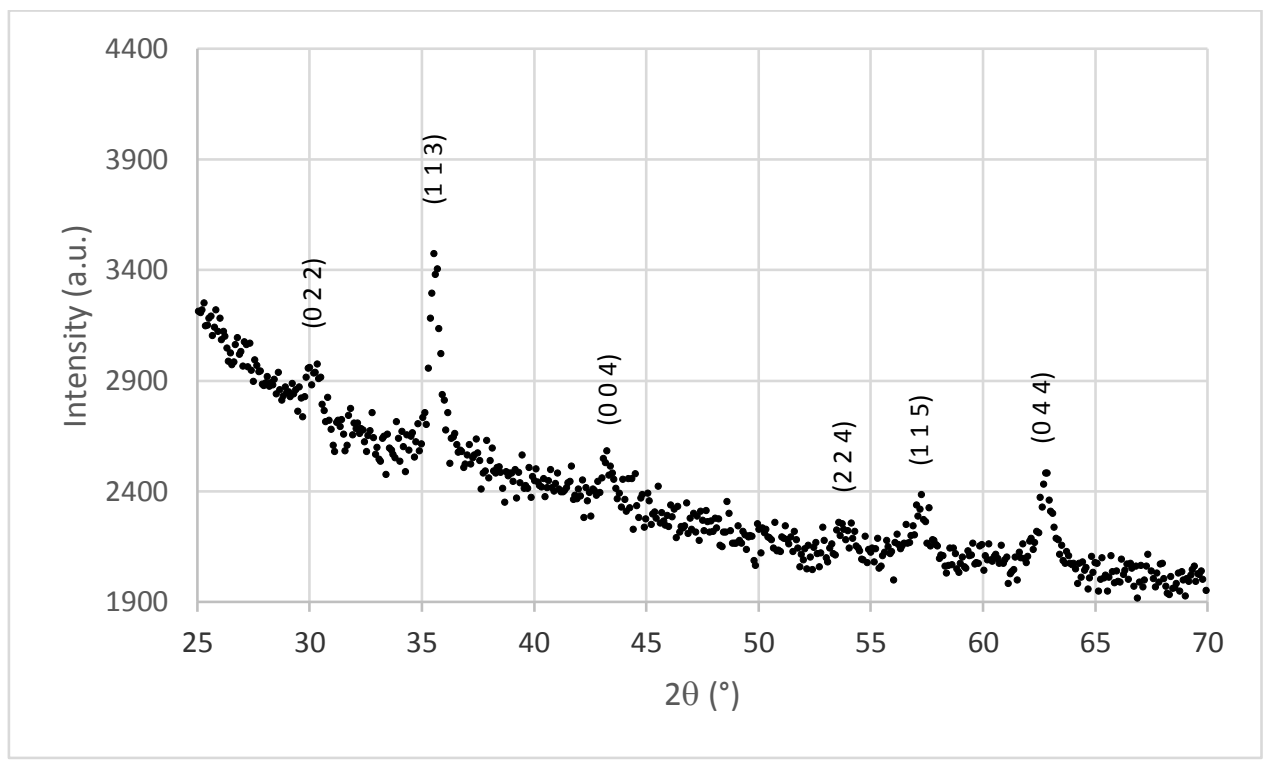

Fig. 3 XRD diagram of magnetic biochar.

An analysis of the XPS Fe2p spectrum (Fig. 4) allowed the nature of the iron oxide to be identified. The peaks at bonding energies of $710.9 \mathrm{eV}$ and $724.6 \mathrm{eV}$ corresponded, respectively, to the main components $\mathrm{Fe} 2 \mathrm{p}_{3 / 2}$ and $\mathrm{Fe} 2 \mathrm{p}_{1 / 2}$ of iron oxide $\mathrm{Fe}_{2} \mathrm{O}_{3}$. According to Grosvenor et al. [51], magnetite can be distinguished from maghemite by the position of the satellite peak between the two main peaks. Here the difference between the satellite and the $\mathrm{Fe} 2 \mathrm{p}_{3 / 2}$ peak is $8.4(+/-0.2) \mathrm{eV}$, which corresponds to maghemite (for which Grosvenor measured $8.3 \mathrm{eV}$, while for magnetite, the difference is much smaller at only $5.9 \mathrm{eV}$ ). 


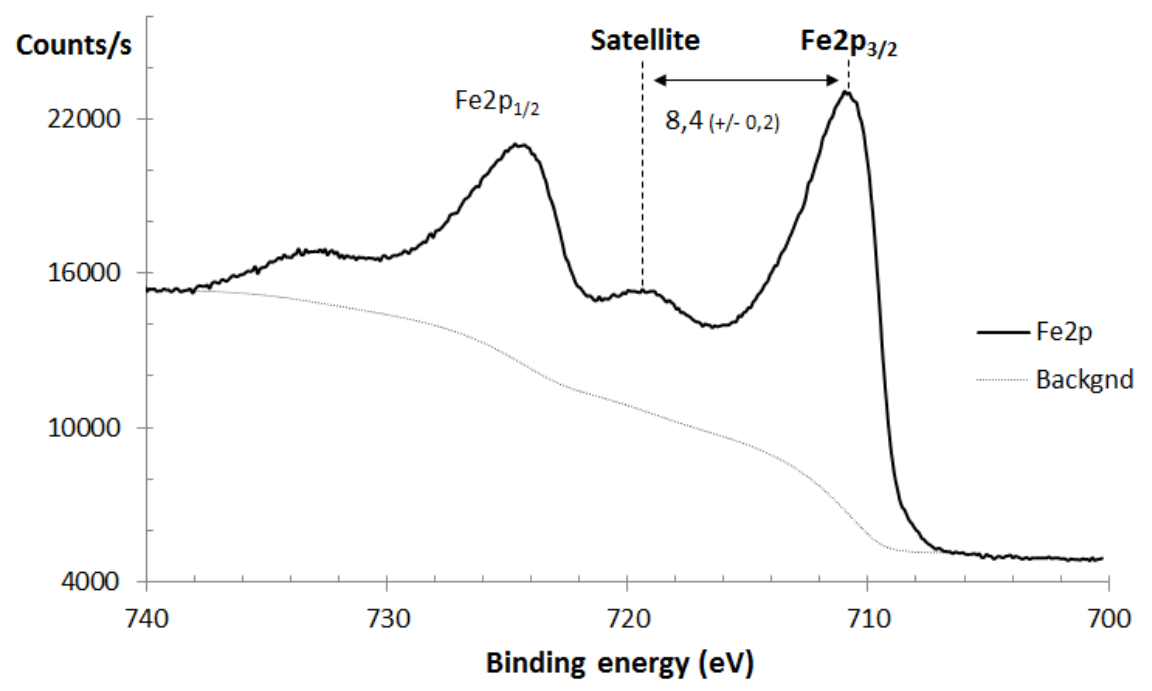

Fig. 4 Fe2p XPS spectra of magnetic biochar

SEM images give us further insight into ground biochar and magnetic biochar morphology and composition (Fig. 5 and Fig. 6). The non-magnetic biochar appears as an entanglement of carbon cell walls of different thicknesses (Fig. 5.a). For magnetic biochar, the carbon sheets did not appear to be uniformly covered with the iron oxide nanoparticle layer (Fig. 5.b), but the presence of iron was highlighted by EDX analyses (Fig. 6.b). Relative abundances (in atomic percentage) of C, O, Fe for non-magnetic and magnetic biochar were 56/44/0 and 17/60/23, respectively. The size distribution of the magnetic biochar particles was also determined using successive sieves. The mean particle diameter was $150 \mu \mathrm{m}$, and $95 \%$ of the particles had a diameter between 45 and 400 $\mu \mathrm{m}$. This is in agreement with the SEM images.
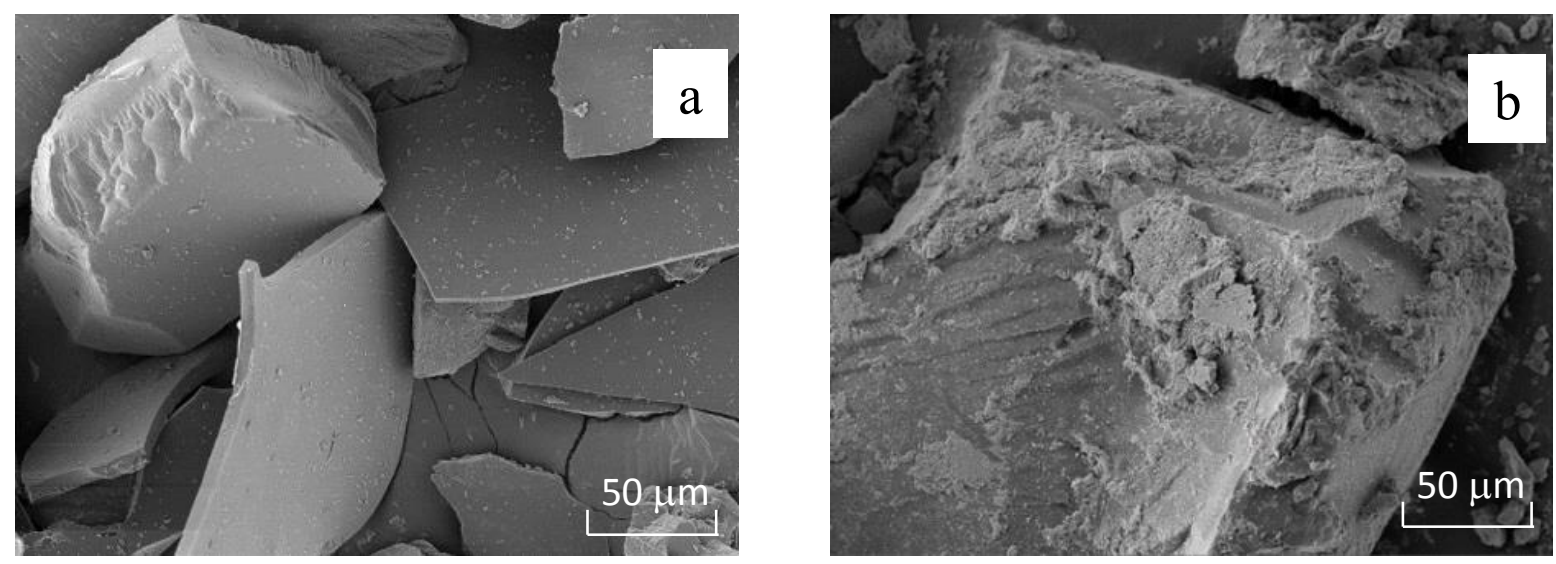

Fig. 5 SEM images of a) non-magnetic biochar and b) magnetic biochar 


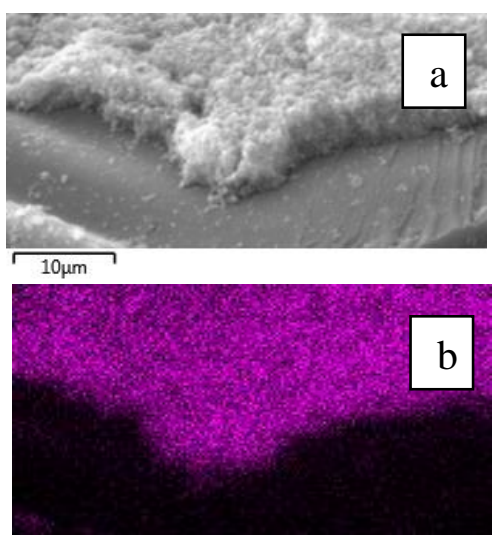

Fig. 6 SEM pictures (a) and the corresponding EDX Fe map (b) of the magnetic biochar surface highlighting the presence of iron (coloured zone)

The magnetic properties of magnetic biochar were measured using VSM (Fig. 7).

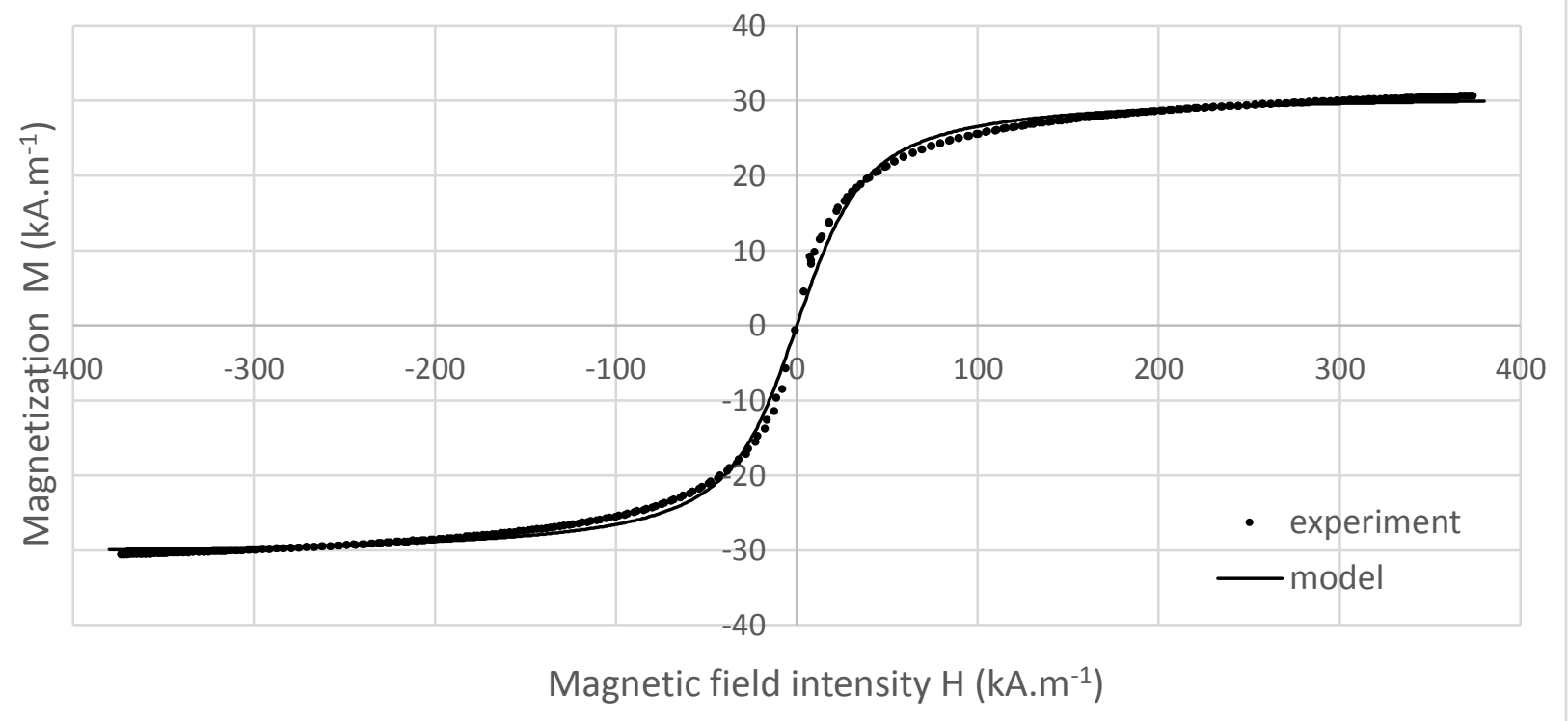

Fig. 7 Magnetization curve of magnetic biochar (experiment and Langevin modelling)

The magnetization curve exhibits no hysteresis, meaning that magnetic biochar has superparamagnetic properties (Fig. 7). Fitting the experimental magnetization curve with the Langevin function revealed that the mean particle size of the magnetic nanoparticles was close to $11 \mathrm{~nm}$. It is known that magnetic iron oxide (magnetite or maghemite) nanoparticles show superparamagnetic behaviour at this particle size [40], implying the superparamagnetic behaviour of the whole biochar composite. The saturation magnetization of the magnetic biochar was found 
to be $\mathrm{M}_{\mathrm{S}}=31.1 \mathrm{kA} \cdot \mathrm{m}^{-1}$, which corresponds to the saturation magnetization of constitutive iron oxide nanoparticles $M_{p}=\frac{M_{s}}{\phi}$ varying between 280 and $370 \mathrm{kA} \cdot \mathrm{m}^{-1}$ for the iron oxide volume fraction $\phi$ evaluated between 9 and 12 vol. \% using pycnometry and ICP-AES methods. The upper limit of the $M_{p}$ value is consistent with the saturation magnetization of bulk maghemite.

The zeta potential of magnetic biochar was measured as a function of $\mathrm{pH}$ (Fig. 8). The point of zero charge was determined by interpolation of the $\mathrm{pH}$ value at zeta potential equal to zero. For non-magnetic biochar, the point of zero charge was 2.0 [38], meaning that the biochar matrix has a permanent negative charge from $\mathrm{pH} 2.0$ to $\mathrm{pH} 10$. After surface precipitation of iron oxide, the point of zero charge was 6.9, which is consistent with maghemite point of zero charge [52]. Different values for the point of zero charge for composite (iron oxide/carbonaceous materials) have been reported from the literature, ranging from 4.9 [53] to 6.8 [54]. This large variation in point of zero charge depends on the material preparation method (co-precipitation, solvothermal route etc), and determination method (microelectrophoresis, $\mathrm{pH}$ drift). According to Fig. 8, the surface charge of magnetic biochar is negative from $\mathrm{pH} 6.9$ to more basic $\mathrm{pH}$ values, meaning that electrostatic interactions with cationic species from the solution should be favoured in this $\mathrm{pH}$ range.

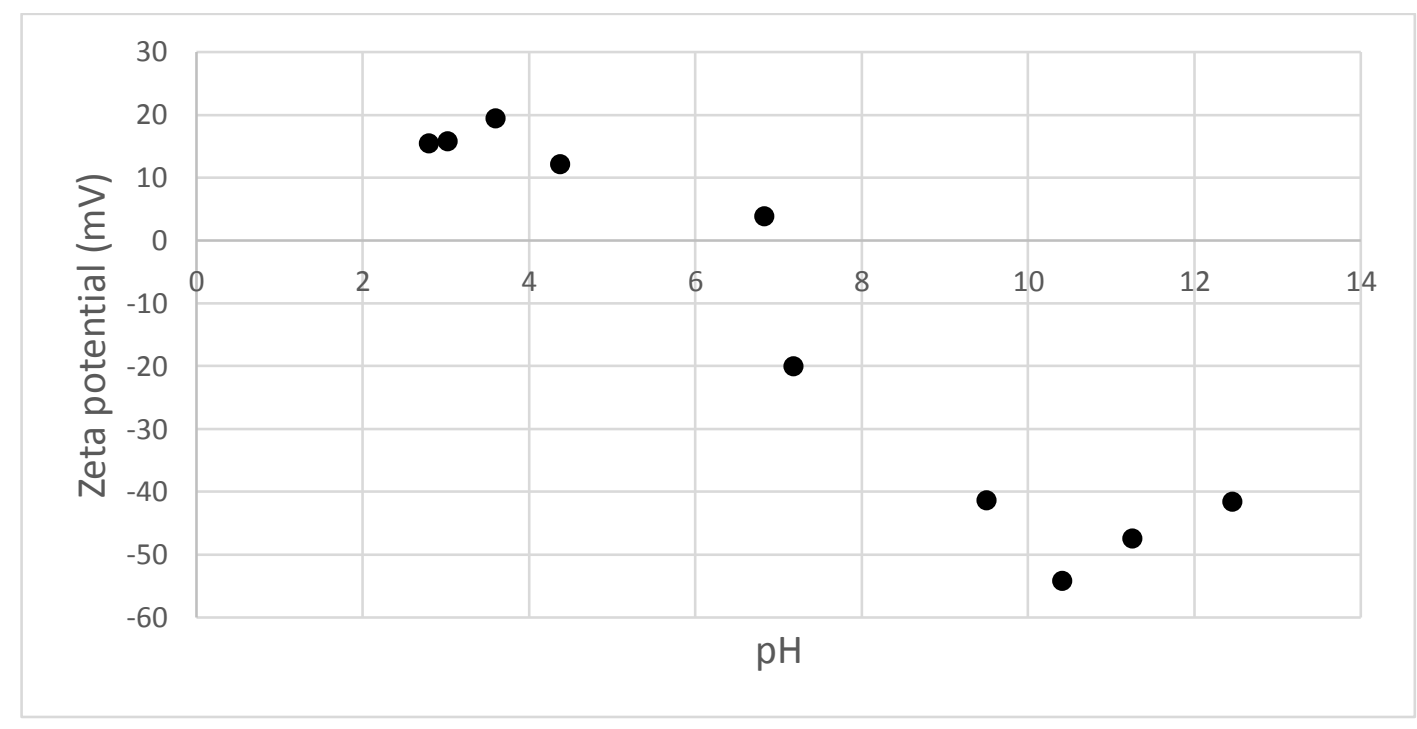

Fig. 8 Zeta potential of magnetic biochar as a function of $\mathrm{pH}$

Regarding the surface properties of the investigated composite, both surface sites from maghemite and from biochar (hydroxyl, lactone, aromatic, carboxyl groups) are expected to interact with 
methylene blue. The negative surface charge from $\mathrm{pH}>6.9$ could be due to deprotonated iron hydroxyl groups from maghemite and deprotonated carboxyl, hydroxyl groups from biochar.

\section{Adsorption of methylene blue}

\section{II.1. Kinetics experiments}

Kinetics of the adsorption of methylene blue onto magnetic biochar was studied for two different initial methylene blue concentrations $C_{0}\left(10^{-4} \mathrm{~mol} . \mathrm{L}^{-1}\right.$ and $\left.2 \cdot 10^{-5} \mathrm{~mol} . \mathrm{L}^{-1}\right)$ at $\mathrm{pH}$, and the $\mathrm{pH}$ effect was tested by performing experiments for two different $\mathrm{pH}$ values (2 and 6) at an initial concentration of $2 \cdot 10^{-5} \mathrm{~mol} . \mathrm{L}^{-1}$.

The experimental values of $q_{t}$ (quantity of adsorbed methylene blue in moles per gram of magnetic biochar, at time $t$ ) as a function of contact time, are presented on Fig. 9, together with a non-linear modelling using either the pseudo-first order model or the pseudo-second order model. The experimental data show faster kinetics for $C_{0}=2 \cdot 10^{-5}$ mol. $\mathrm{L}^{-1}$ and $\mathrm{pH} 6$ since a plateau is reached in approximately $1.5 \mathrm{~h}$ while the kinetics for a higher concentration or a more acidic $\mathrm{pH}$ is slower, with the plateau generally being reached after approximately 1 day.

The calculated rate constants for the two models and the corresponding correlation coefficient $\mathrm{R}^{2}$ values are presented in Table 1 together with data from the literature obtained on biochar samples of different origins.

Table 1 shows that the modelling of the adsorption of methylene blue onto different types of biochars from previous studies gives, in most cases, better results with the pseudo-second order than with the pseudo-first order model. It should nevertheless be noted that the linear form of the kinetic equation was usually preferred, which favours the modelling with pseudo-second order kinetics $[44,45]$. Table 1 shows that the $k_{1}$ values range from 0.270 to $4.00 \mathrm{~h}^{-1}$, whereas the $k_{2}$ value range from $2.23 \cdot 10^{3}$ to $2.06 \cdot 10^{7} \mathrm{~g} \cdot \mathrm{mol}^{-1} \cdot \mathrm{h}^{-1}$. The $k_{1}$ and $k_{2}$ values determined in this study for $\mathrm{C}_{0}=2 \cdot 10^{-5} \mathrm{~mol} \cdot \mathrm{L}^{-1}$ and $\mathrm{pH}=6\left(k_{1}=4.00 \mathrm{~h}^{-1}\right.$ and $\left.k_{2}=1.91 \cdot 10^{6} \mathrm{~g} \cdot \mathrm{mol}^{-1} \cdot \mathrm{h}^{-1}\right)$, are thus among the highest previously reported values (Table 1), confirming the fast kinetics for this system. The values obtained in this study for the other experimental conditions (higher $\mathrm{C}_{0}$ or lower $\mathrm{pH}$ ), were in the range of those from previous studies.

In this study, for the lowest initial concentration at $\mathrm{pH} 6$ (Fig. 9.a), the experimental $\mathrm{q}_{\mathrm{t}}$ values are better modelled by the pseudo-first order model $\left(\mathrm{R}^{2}=0.972\right)$ than by the pseudo-second order model $\left(\mathrm{R}^{2}=0.918\right)$. For $\mathrm{pH} 2$ at the same concentration (Fig. 9.c), the pseudo-second order model gives a better description of the data $\left(\mathrm{R}^{2}=0.962\right.$, versus $\mathrm{R}^{2}=0.865$ for pseudo-first order model). 
For the higher concentration at pH 6 (Fig. 9.b), both models satisfactorily fit the experimental data $\left(\mathrm{R}^{2}=0.975\right.$ for pseudo-first order and $\mathrm{R}^{2}=0.982$ for pseudo-second order).

For all models, the calculated rate constants (Table 1) were the highest for the lowest initial concentration at $\mathrm{pH}=6$, while they are the lowest for the higher concentration at $\mathrm{pH}=6$. This is likely in agreement with a slowed sorption as the surface sites were progressively saturated.

For the two $\mathrm{pH}$ values for $\mathrm{C}_{0}=2 \cdot 10^{-5} \mathrm{~mol} . \mathrm{L}^{-1}$, there was a clear change in both the rate constant values and in the quality of the modelling using either the pseudo-first order or the pseudo-second order model. Indeed, the pseudo-first order model had a much better fit for the data recorded at $\mathrm{pH}=6$ than the pseudo second-order model, while the pseudo-second order was more appropriate than the first-order model to describe the data recorded at $\mathrm{pH}=2$. This could correspond to a change in the sorption mechanism. When the zeta potential measurements were analysed, the $\mathrm{pH}$ of the point of zero charge of the magnetic biochar was found to be around 6, resulting in a positively charged surface at $\mathrm{pH}=2$. This would result in an electrostatic repulsion for low $\mathrm{pH}$ values between the sorbent surface and the sorbate, a cationic dye, which could explain the slower kinetics at $\mathrm{pH}$ $=2$. There might also be a change between $\mathrm{pH}=2$ and $\mathrm{pH}=6$ in the nature of surface sites to which methylene blue binds. Indeed, the $\mathrm{pH}$ of the point of zero charge of the two composite constituent materials, biochar and iron oxide (maghemite), are respectively 2.0 and around 6-7 [52]. Sorption could then be favoured for lower $\mathrm{pH}$ values on the biochar part of the composite through $\pi-\pi$ stacking or hydrogen bonding [55-57], while electrostatic interactions with both biochar and iron oxide parts of the composite would be possible for higher $\mathrm{pH}$ values. 
Table 1: Comparison of kinetic modelling results obtained for methylene blue adsorption on various biochars. $\left(\mathrm{C}_{0}\right.$ : initial methylene blue concentration, $\mathrm{V} / \mathrm{m}$ : ratio between suspension volume and mass of the sorbent, n.s.: not specified, I: pseudo-first order model, II: pseudo-second order model).

\begin{tabular}{|c|c|c|c|c|c|}
\hline Adsorbent & Experimental conditions & Best fit & $\begin{array}{c}k_{l} \text { value } \\
\left(\mathrm{h}^{-1}\right)\end{array}$ & $\begin{array}{c}k_{2} \text { value } \\
\left(\mathrm{g} \cdot \mathrm{mol}^{-1} \cdot \mathrm{h}^{-1}\right)\end{array}$ & Reference \\
\hline $\begin{array}{l}\text { Biochar from municipal } \\
\text { sewage sludge and tea waste }\end{array}$ & $\begin{array}{c}\mathrm{T}=25^{\circ} \mathrm{C}, \mathrm{pH}=\text { n.s. } \\
\mathrm{C}_{0}=1.5 \cdot 10^{-4} \text { mol.L } \mathrm{L}^{-1} \\
\mathrm{~V} / \mathrm{m}=10 \mathrm{~g} . \mathrm{L}^{-1}\end{array}$ & $\begin{array}{c}\text { II } \\
\text { (linear fit) }\end{array}$ & $\begin{array}{c}0.539 \\
\left(\mathrm{R}^{2}=0.929\right)\end{array}$ & $\begin{array}{c}5.99 \cdot 10^{5} \\
\left(\mathrm{R}^{2}=1.000\right)\end{array}$ & [58] \\
\hline Oxidized biochar from weeds & $\begin{array}{c}\mathrm{T}=20^{\circ} \mathrm{C}, \mathrm{pH}=7.4, \\
\mathrm{C}_{0}=1.6 \cdot 10^{-4} \mathrm{~mol} . \mathrm{L}^{-1}, \\
\mathrm{~V} / \mathrm{m}=2 \mathrm{~g} . \mathrm{L}^{-1}\end{array}$ & $\begin{array}{c}\text { II } \\
\text { (linear fit) }\end{array}$ & $\begin{array}{c}0.438 \\
\left(\mathrm{R}^{2}=0.976\right)\end{array}$ & $\begin{array}{c}2.21 \cdot 10^{4} \\
\left(\mathrm{R}^{2}=0.988\right)\end{array}$ & [59] \\
\hline Wheat straw biochar & $\begin{array}{c}\mathrm{T}=25^{\circ} \mathrm{C}, \mathrm{pH}=3 \\
\mathrm{C}_{0}=3.1 \cdot 10^{-5} \mathrm{~mol} . \mathrm{L}^{-1}, \\
\mathrm{~V} / \mathrm{m}=0.4 \mathrm{~g} . \mathrm{L}^{-1}\end{array}$ & $\begin{array}{c}\text { II } \\
\text { (non- } \\
\text { linear fit) }\end{array}$ & $\begin{array}{c}0.3 \\
\left(\mathrm{R}^{2}=0.897\right)\end{array}$ & $\begin{array}{c}9.18 \cdot 10^{3} \\
\left(\mathrm{R}^{2}=0.944\right)\end{array}$ & [60] \\
\hline Wheat straw biochar & $\begin{array}{c}\mathrm{T}=25^{\circ} \mathrm{C}, \mathrm{pH}=7, \\
\mathrm{C}_{0}=3.1 \cdot 10^{-5} \mathrm{~mol} . \mathrm{L}^{-1}, \\
\mathrm{~V} / \mathrm{m}=0.4 \mathrm{~g} . \mathrm{L}^{-1}\end{array}$ & $\begin{array}{c}\text { II } \\
\text { (non- } \\
\text { linear fit) }\end{array}$ & $\begin{array}{c}1.04 \\
\left(\mathrm{R}^{2}=0.856\right)\end{array}$ & $\begin{array}{c}2.51 \cdot 10^{4} \\
\left(\mathrm{R}^{2}=0.930\right)\end{array}$ & [60] \\
\hline $\begin{array}{l}\text { Granular sludge-based } \\
\text { biochar }\end{array}$ & $\begin{array}{c}\mathrm{T}=25^{\circ} \mathrm{C}, \mathrm{pH}=6, \\
\mathrm{C}_{0}=6.3 \cdot 10^{-5} \mathrm{~mol} . \mathrm{L}^{-1}, \\
\mathrm{~V} / \mathrm{m}=0.4 \mathrm{~g} . \mathrm{L}^{-1}\end{array}$ & $\begin{array}{c}\text { II } \\
\text { (linear fit) }\end{array}$ & $\begin{array}{c}2.26 \\
\left(\mathrm{R}^{2}=0.932\right)\end{array}$ & $\begin{array}{c}1.65 \cdot 10^{6} \\
\left(\mathrm{R}^{2}=1.000\right)\end{array}$ & [61] \\
\hline $\begin{array}{l}\text { Biochar from digestion } \\
\text { residue of food waste and } \\
\text { Chinese silver grass }\end{array}$ & $\begin{array}{c}\mathrm{T}=40^{\circ} \mathrm{C}, \mathrm{pH}=\mathrm{n} . \mathrm{s} . \\
\mathrm{C}_{0}=1.6 \cdot 10^{-5} \mathrm{~mol} \cdot \mathrm{L}^{-1}, \\
\mathrm{~V} / \mathrm{m}=8 \mathrm{~g} \cdot \mathrm{L}^{-1}\end{array}$ & $\begin{array}{l}\text { II (linear } \\
\text { fit) }\end{array}$ & $\begin{array}{c}1.56 \\
\left(\mathrm{R}^{2}=0.840\right)\end{array}$ & $\begin{array}{c}2.06 \cdot 10^{7} \\
\left(\mathrm{R}^{2}=1.000\right)\end{array}$ & [1] \\
\hline Biochar from palm bark & $\begin{array}{c}\mathrm{T}=40^{\circ} \mathrm{C}, \mathrm{pH}=\mathrm{n} . \mathrm{s} . \\
\mathrm{C}_{0}=1.6 \cdot 10^{-5} \mathrm{~mol} . \mathrm{L}^{-1} \\
\mathrm{~V} / \mathrm{m}=8 \mathrm{~g} . \mathrm{L}^{-1}\end{array}$ & $\begin{array}{l}\text { II (linear } \\
\text { fit) }\end{array}$ & $\begin{array}{c}1.25 \\
\left(\mathrm{R}^{2}=0.946\right)\end{array}$ & $\begin{array}{c}5.89 \cdot 10^{6} \\
\left(R^{2}=0.999\right)\end{array}$ & [1] \\
\hline Biochar from eucalyptus & $\begin{array}{c}\mathrm{T}=40^{\circ} \mathrm{C}, \mathrm{pH}=\mathrm{n} . \mathrm{s} . \\
\mathrm{C}_{0}=1.6 \cdot 10^{-5} \mathrm{~mol} . \mathrm{L}^{-1} \\
\mathrm{~V} / \mathrm{m}=8 \mathrm{~g} . \mathrm{L}^{-1}\end{array}$ & $\begin{array}{l}\text { II (linear } \\
\text { fit) }\end{array}$ & $\begin{array}{c}0.960 \\
\left(R^{2}=0.883\right)\end{array}$ & $\begin{array}{c}6.36 \cdot 10^{6} \\
\left(R^{2}=0.998\right)\end{array}$ & [1] \\
\hline $\begin{array}{l}\text { Vermicompost-derived } \\
\text { biochar pyrolysed at } 300^{\circ} \mathrm{C}\end{array}$ & $\begin{array}{c}\mathrm{T}=25^{\circ} \mathrm{C}, \mathrm{pH}=7 \\
\mathrm{C}_{0}=\text { n.s. } \\
\mathrm{V} / \mathrm{m}=1.5 \text { g. } \mathrm{L}^{-1}\end{array}$ & $\begin{array}{l}\text { II (linear } \\
\text { fit) }\end{array}$ & $\begin{array}{c}0.270 \\
\left(\mathrm{R}^{2}=0.234\right)\end{array}$ & $\begin{array}{c}6.34 \cdot 10^{5} \\
\left(\mathrm{R}^{2}=1.000\right)\end{array}$ & [2] \\
\hline $\begin{array}{l}\text { Biochar/AlOOH } \\
\text { nanocomposite }\end{array}$ & $\begin{array}{c}\mathrm{T}=22^{\circ} \mathrm{C}, \mathrm{pH}=\mathrm{n} . \mathrm{s} . \\
\mathrm{C}_{0}=1.6 \cdot 10^{-4} \mathrm{~mol} . \mathrm{L}^{-1}, \\
\mathrm{~V} / \mathrm{m}=2 \mathrm{~g} . \mathrm{L}^{-1}\end{array}$ & $\begin{array}{c}\text { I and II } \\
\text { (non- } \\
\text { linear fit) }\end{array}$ & $\begin{array}{c}0.8 \\
\left(\mathrm{R}^{2}=0.975\right)\end{array}$ & $\begin{array}{c}2.23 \cdot 10^{3} \\
\left(\mathrm{R}^{2}=0.978\right)\end{array}$ & [62] \\
\hline $\begin{array}{l}\text { Humins-derived magnetic } \\
\text { biochar }\end{array}$ & $\begin{array}{c}\mathrm{T}=23^{\circ} \mathrm{C}, \mathrm{pH}=6, \\
\mathrm{C}_{0}=2.10^{-5} \mathrm{~mol} . \mathrm{L}^{-1}, \\
\mathrm{~V} / \mathrm{m}=5 \mathrm{~g} . \mathrm{L}^{-1}\end{array}$ & $\begin{array}{c}\text { I } \\
\text { (non- } \\
\text { linear fit) }\end{array}$ & $\begin{array}{c}4.00 \\
\left(\mathrm{R}^{2}=0.972\right)\end{array}$ & $\begin{array}{c}1.91 \cdot 10^{6} \\
\left(\mathrm{R}^{2}=0.918\right)\end{array}$ & This study \\
\hline $\begin{array}{l}\text { Humins-derived magnetic } \\
\text { biochar }\end{array}$ & $\begin{array}{c}\mathrm{T}=23^{\circ} \mathrm{C}, \mathrm{pH}=6 \\
\mathrm{C}_{0}=10^{-4} \mathrm{~mol} . \mathrm{L}^{-1} \\
\mathrm{~V} / \mathrm{m}=5 \mathrm{~g} . \mathrm{L}^{-1}\end{array}$ & $\begin{array}{l}\text { I and II } \\
\text { (non- } \\
\text { linear fit) }\end{array}$ & $\begin{array}{c}0.308 \\
\left(\mathrm{R}^{2}=0.975\right)\end{array}$ & $\begin{array}{c}2.11 \cdot 10^{4} \\
\left(\mathrm{R}^{2}=0.982\right)\end{array}$ & This study \\
\hline $\begin{array}{l}\text { Humins-derived magnetic } \\
\text { biochar }\end{array}$ & $\begin{array}{c}\mathrm{T}=23^{\circ} \mathrm{C}, \mathrm{pH}=2, \\
\mathrm{C}_{0}=2 \cdot 10^{-5} \mathrm{~mol} . \mathrm{L}^{-1}, \\
\mathrm{~V} / \mathrm{m}=5 \mathrm{~g} . \mathrm{L}^{-1}\end{array}$ & $\begin{array}{c}\text { II } \\
\text { (non- } \\
\text { linear fit) }\end{array}$ & $\begin{array}{c}0.548 \\
\left(\mathrm{R}^{2}=0.865\right)\end{array}$ & $\begin{array}{c}1.87 \cdot 10^{5} \\
\left(\mathrm{R}^{2}=0.962\right)\end{array}$ & This study \\
\hline
\end{tabular}



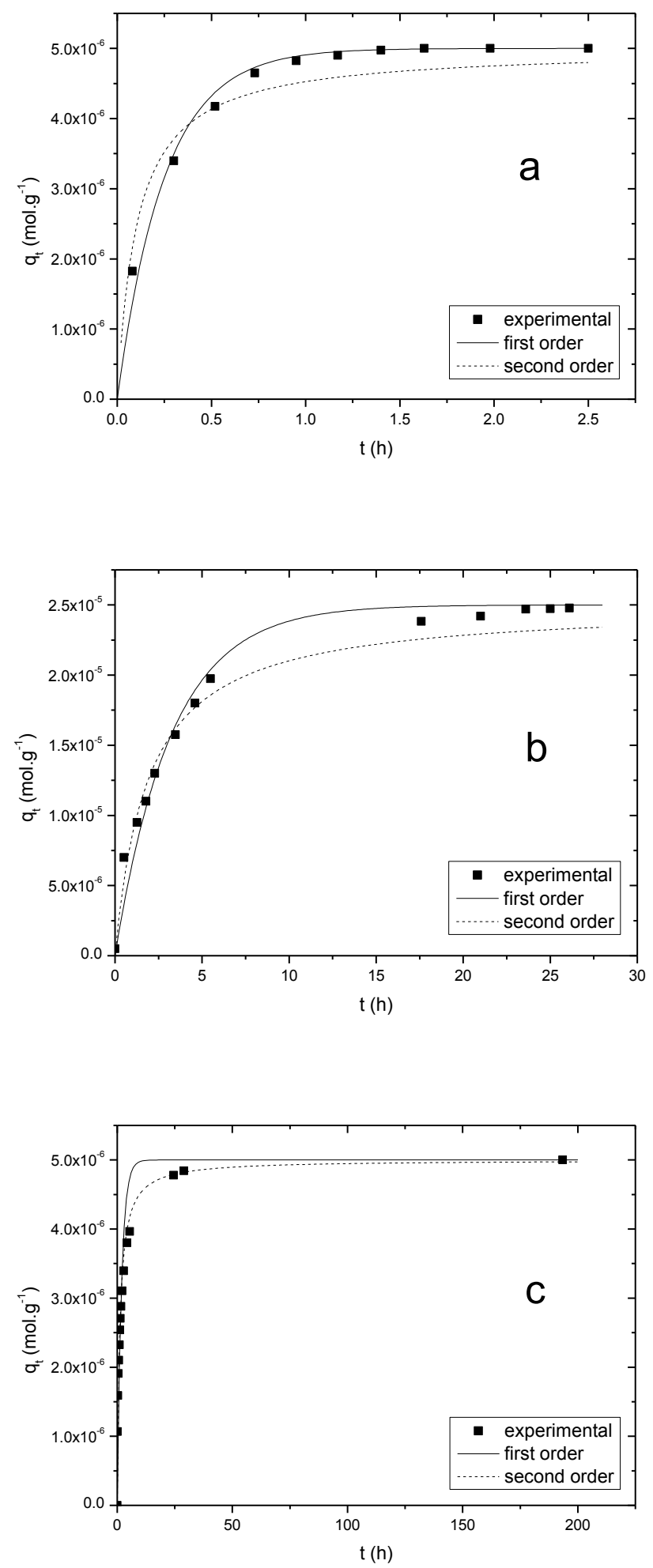

Fig. 9 Kinetic data and modeling of the adsorption of methylene blue onto magnetic biochar (a: $\mathrm{C}_{0}=2 \cdot 10^{-5}$ mol. $\mathrm{L}^{-1} ; \mathrm{pH}=6 / \mathrm{b}: \mathrm{C}_{0}=10^{-4} \mathrm{~mol} . \mathrm{L}^{-1} ; \mathrm{pH}=6 / \mathrm{c}: \mathrm{C}_{0}=2 \cdot 10^{-5}$ mol. $\mathrm{L}^{-1} ; \mathrm{pH}=2$ ) 


\section{II.2. Adsorption isotherm}

The adsorption isotherm recorded at $\mathrm{pH}=6$ is shown on Fig. 10, together with model simulations. When the initial concentration of methylene blue is increased, the adsorption isotherm tends towards a plateau, meaning that the surface becomes nearly saturated. In the range of studied concentrations, the adsorption isotherm is satisfactorily described with both Langmuir and Freundlich models and is in good accordance with other studies on various biochars (Table 2).

The comparison of the Langmuir model with parameters from the literature show that the maximum adsorption capacity $\left(q_{\max }\right)$ obtained in this study $\left(3.35 \cdot 10^{-5} \mathrm{~mol} . \mathrm{g}^{-1}\right.$, i.e. $\left.10.7 \mathrm{mg} \cdot \mathrm{g}^{-1}\right)$ is in the range of other values from the literature $\left(6.44 \cdot 10^{-6}-5.45 \cdot 10^{-4}\right.$ mol.g ${ }^{-1}$ i.e. $\left.2.1-174.3 \mathrm{mg} . \mathrm{g}^{-1}\right)$. The Langmuir constant, $K_{L}$, is related to the affinity of the sorbate with the surface when the sorbate concentration is low. The Langmuir constant determined in this study $\left(2.33 \cdot 10^{4} \mathrm{~L}^{\mathrm{mol}}{ }^{-1}\right)$ is comparable to values from the literature $\left(6.08 \cdot 10^{3}-2.02 \cdot 10^{5} \mathrm{~L}^{\mathrm{mol}}{ }^{-1}\right)$. The Freundlich constant, $K_{F}$, is also higher when the affinity of the sorbate with the surface is higher, and the Freundlich constant determined in this study $\left(K_{F}=5.7010^{-5} \mathrm{~mol}^{0.913} \cdot \mathrm{L}^{0.087} \cdot \mathrm{g}^{-1}\right)$ is in the range of other values from the literature ( $K_{F}$ values: $\left.1.12 \cdot 10^{-5}-0.116 \mathrm{~mol}^{1-\mathrm{n}} \cdot \mathrm{L}^{\mathrm{n}} \cdot \mathrm{g}^{-1}\right)$.

The Langmuir and Freundlich modelling results show that the biochar studied in this work has interesting adsorption properties for methylene blue even if the maximum adsorption capacity and affinity constants were not among the highest obtained in the literature. This could be counterbalanced by the fast adsorption kinetics which make the material suitable for the design of a water purification process. 


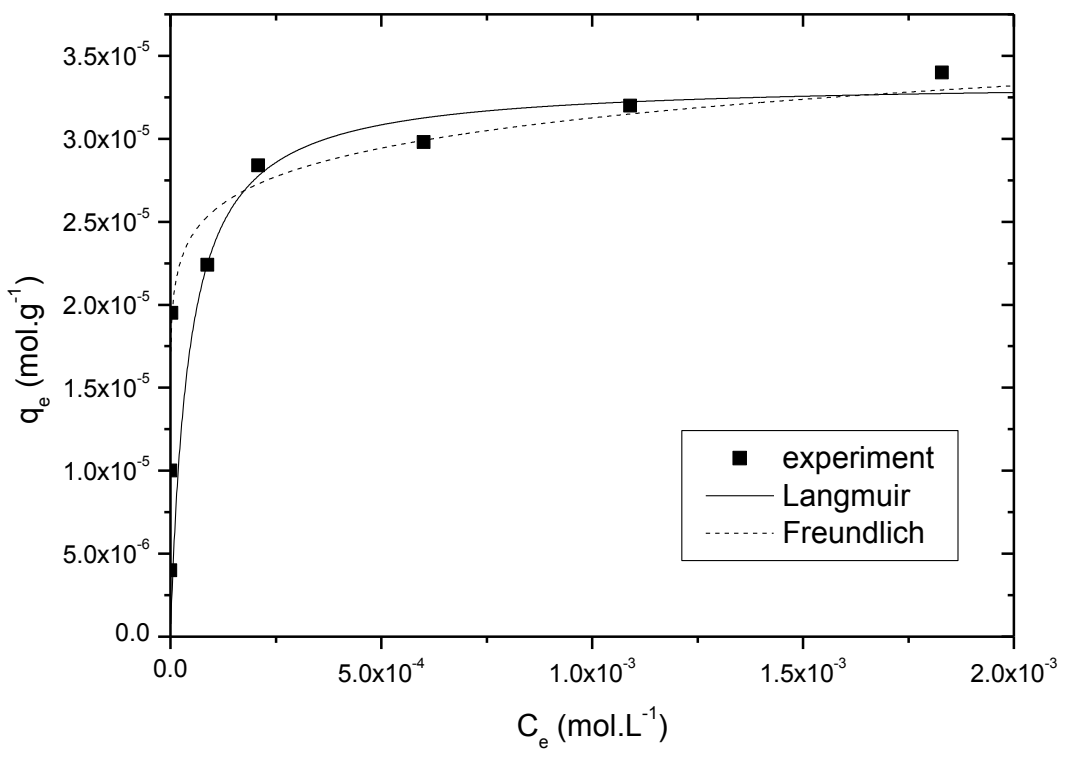

Fig. 10 Adsorption isotherm of methylene blue onto magnetic biochar (experiment and modelling) 
Table 2: Comparison of adsorption isotherm parameters obtained for methylene blue adsorption on various biochar samples.

\begin{tabular}{|c|c|c|c|c|c|}
\hline \multirow[t]{2}{*}{ Adsorbent } & \multicolumn{2}{|c|}{$\begin{array}{l}\text { Langmuir } \\
\text { parameters }\end{array}$} & \multicolumn{2}{|c|}{$\begin{array}{l}\text { Freundlich } \\
\text { parameters }\end{array}$} & \multirow[t]{2}{*}{ Reference } \\
\hline & $\begin{array}{c}q_{\max } \\
\left(\mathrm{mol} \cdot \mathrm{g}^{-1}\right)\end{array}$ & $\begin{array}{c}K_{L} \\
\left(\mathrm{~L} . \mathrm{mol}^{-1}\right) \\
\end{array}$ & $\begin{array}{c}K_{F} \\
\left(\mathrm{~mol}^{1-\mathrm{n}} \cdot \mathrm{L}^{\mathrm{n}} \cdot \mathrm{g}^{-1}\right) \\
\end{array}$ & $n$ & \\
\hline $\begin{array}{l}\text { Biochar from municipal sewage } \\
\text { sludge and tea waste }\end{array}$ & \multicolumn{2}{|c|}{$\left(\mathrm{R}^{2}=0.99\right)$} & \multicolumn{2}{|c|}{$\left(\mathrm{R}^{2}=0.81\right)$} & [58] \\
\hline Oxidized biochar from weeds & \multicolumn{2}{|c|}{$\left(\mathrm{R}^{2}=1.00\right)$} & \multicolumn{2}{|c|}{$\left(\mathrm{R}^{2}=0.91\right)$} & [59] \\
\hline Wheat straw biochar & $\begin{array}{c}1.46 \cdot 10^{-4} \\
\left(\mathrm{R}^{2}=\right.\end{array}$ & $\left(\mathrm{R}^{2}=0.92\right)$ & $\begin{array}{l}1.00 \cdot 10^{-3} \\
\left(\mathrm{R}^{2}=0.9\right.\end{array}$ & 0.220 & {$[60]$} \\
\hline Granular sludge-based biochar & \multicolumn{2}{|c|}{$\left(\mathrm{R}^{2}=0.99\right)$} & \multicolumn{2}{|c|}{$\left(\mathrm{R}^{2}=0.83\right)$} & {$[61]$} \\
\hline $\begin{array}{l}\text { Biochar from digestion residue of } \\
\text { food waste and Chinese silver grass }\end{array}$ & $\begin{array}{r}2.97 \cdot 10^{-5} \\
\left(\mathrm{R}^{2}=\right.\end{array}$ & $\begin{array}{l}3.17 \cdot 10^{4} \\
0.97)\end{array}$ & $\begin{array}{r}9.62 \cdot 10^{-5} \\
\left(\mathrm{R}^{2}=0.9\right.\end{array}$ & 0.174 & {$[1]$} \\
\hline Biochar from palm bark & \multicolumn{2}{|c|}{$\left(\mathrm{R}^{2}=0.99\right)$} & \multicolumn{2}{|c|}{$\left(\mathrm{R}^{2}=0.91\right)$} & [1] \\
\hline Biochar from eucalyptus & \multicolumn{2}{|c|}{$\left(\mathrm{R}^{2}=0.99\right)$} & \multicolumn{2}{|c|}{$\left(\mathrm{R}^{2}=0.89\right)$} & [1] \\
\hline $\begin{array}{l}\text { Vermicompost-derived biochar } \\
\text { pyrolysed at } 300^{\circ} \mathrm{C}\end{array}$ & $\begin{array}{r}5.45 \cdot 10^{-4} \\
\left(\mathrm{R}^{2}=\right.\end{array}$ & $\begin{array}{l}6.27 \cdot 10^{4} \\
0.99)\end{array}$ & \multicolumn{2}{|c|}{$\left(\mathrm{R}^{2}=0.91\right)$} & [2] \\
\hline Biochar/AlOOH nanocomposite & $\begin{array}{c}2.66 \cdot 10^{-4} \\
\left(\mathrm{R}^{2}=\right.\end{array}$ & $\left(\mathrm{R}^{2}=0.97\right)$ & \multicolumn{2}{|c|}{$\left(R^{2}=0.96\right)$} & {$[62]$} \\
\hline Humins-derived magnetic biochar & $\begin{array}{r}3.35 \cdot 10^{-5} \\
\left(\mathrm{R}^{2}=\right.\end{array}$ & $\begin{array}{l}2.33 \cdot 10^{4} \\
0.97)\end{array}$ & $\begin{array}{l}5.70 \cdot 10^{-5} \\
\left(\mathrm{R}^{2}=0.9\right.\end{array}$ & 0.087 & This study \\
\hline
\end{tabular}




\section{Magnetic separation}

Magnetic separation experiments were first carried out on bare particles (magnetic biochar suspensions without methylene blue) in order to determine the optimum flow rate and magnetic field to ensure the capture of the particles. A complete experiment, combining adsorption and magnetic separation was then performed where optimum flow rate and magnetic field were applied.

\section{III.1 Magnetic separation of the bare particles}

The critical value of the magnetic field $H_{c}$ (value of applied magnetic field above which all the particles are collected by the filter) was determined as a function of the flow rate $Q$, as reported in Fig. 11.

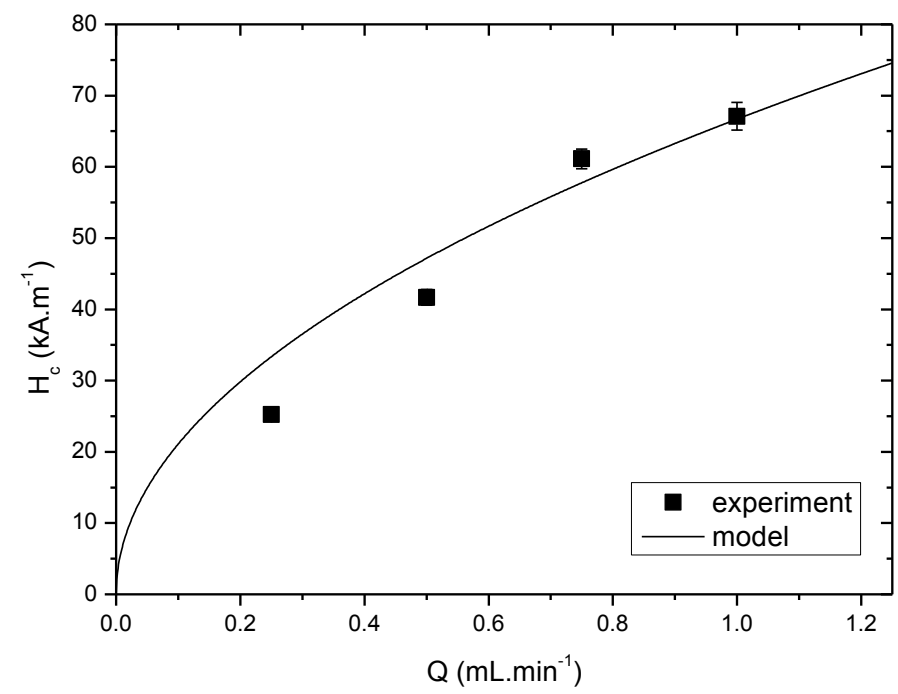

Fig. 11 Critical magnetic field $\left(H_{C}\right)$ as a function of flow rate $(Q)$ : experimental data and modelling

Magnetic separation has been described in terms of a scaling law involving the Mason number, which is defined as the characteristic ratio between hydrodynamic and magnetic forces [63]. The model employs the equilibrium between magnetic and hydrodynamic forces and supposes that all the magnetic biochar particles are captured at a fixed value of the Mason number, as detailed below. This type of modelling has been applied to the experimental data presented on Fig. 11. If the scaling 
law fits well with the experimental data, then the magnetic field that must be applied in order to capture all magnetic biochar particles can be calculated from the imposed flow rate (and reciprocally) to give a model that is useful for optimizing the magnetic separation device.

The magnetic force $F_{m}(\mathrm{~N})$ applied to one particle can be calculated as a function of the gradient of the applied magnetic field $\nabla H \quad\left(\mathrm{~A} . \mathrm{m}^{-2}\right)$ and of the magnetic moment of the magnetic biochar particle $\mu_{\text {part }}\left(\mathrm{T} . \mathrm{m}^{3}\right)$, according to the equation:

$F_{m}=\mu_{\text {part }} \nabla H$

with $\mu_{\text {part }}=\mu_{0} M_{\text {part }} V_{\text {part }} \sim \mu_{0} H d_{\text {part }}{ }^{3}$

where $\mu_{0}$ is the vacuum magnetic permeability $\left(4 \pi \cdot 10^{-7} \mathrm{H} \cdot \mathrm{m}^{-1}\right), M_{\text {part }}, \mathrm{V}_{\text {part }}$ and $\mathrm{d}_{\text {part }}$ are the magnetization $\left(\right.$ A. $\left.\mathrm{m}^{-1}\right)$, volume $\left(\mathrm{m}^{3}\right)$ and diameter $(\mathrm{m})$ of the magnetic biochar particle.

Since

$\nabla H \sim \frac{H}{d_{\text {wire }}}$

where $d_{\text {wire }}$ is the diameter $(m)$ of the nickel wire that composes the magnetic separator, the magnetic force becomes:

$F_{m} \sim \mu_{0} H d_{\text {part }}{ }^{3} \frac{H}{d_{\text {wire }}}=\mu_{0} H^{2} \frac{d_{\text {part }}{ }^{3}}{d_{\text {wire }}}$

The hydrodynamic force $\mathrm{F}_{\mathrm{h}}(\mathrm{N})$ applied to one magnetic biochar particle can be estimated as a Stokes drag force exerted on an immobile magnetic biochar particle placed in a fluid with a flow of velocity $\mathrm{U}\left(\mathrm{m} . \mathrm{s}^{-1}\right)$ :

$F_{h}=3 \pi \eta d_{\text {part }} U \sim \eta d_{\text {part }} U$

where $\eta$ is the dynamic viscosity of the suspending fluid (Pa.s) - water in our case.

The Mason number, which is the ratio between $F_{h}$ and $F_{m}$, can be calculated from Eq. 13 and Eq. 14:

$M a=\frac{F_{h}}{F_{m}} \sim \frac{\eta U d_{\text {wire }}}{\mu_{0} H^{2} d_{\text {part }}^{2}}$

The critical Mason number, $M a_{c}$, is the value below which there is a complete trapping of the magnetic biochar particles by the filter. If the model is correct, then the critical magnetic field $H_{c}$ can be deduced using Eq. 15 from the flow rate $Q=U \cdot S_{\text {tube }}$ with $S_{\text {tube }}\left(\mathrm{m}^{2}\right)$ being the section of the tube of the magnetic separator through which the suspension flows:

$H_{c}{ }^{2}=\frac{\eta d_{\text {wire }}}{\mu_{0} d_{\text {part }}{ }^{2} s_{\text {tube }} M a_{c}} \cdot Q$

The plot of a model consistent with Eq. 16 is represented on Fig. $11\left(H_{c}=66.7 Q^{0.5}, \mathrm{R}^{2}=0.934\right)$ 
It qualitatively reproduces the experimental data, giving a linear behaviour of $H_{C}{ }^{2}$ as a function of $Q$. The scaling law using the Mason number can then be applied to the system and allows to predict the conditions required for complete capture of the magnetic biochar particles by the magnetic separation system.

\section{III.2. Magnetic separation combined with adsorption}

According to the results obtained for the adsorption of methylene blue (see section II), and given the results and scaling law developed in section III.1 on the magnetic separation, experimental conditions were chosen to test any potential effect of (i) the magnetic separation on the adsorption efficiency, and (ii) the adsorption on the magnetic filtration efficiency. To achieve this, suspensions of magnetic biochar previously reacted with a $10 \mathrm{mg} \cdot \mathrm{L}^{-1}\left(3.13 \cdot 10^{-5} \mathrm{~mol} . \mathrm{L}^{-1}\right)$ methylene blue solution ( $12 \mathrm{~h}$ contact time, $100 \%$ adsorption) were pushed through the magnetic separator at a 0.5 mL.min ${ }^{-1}$ flow rate and with a $70 \mathrm{kA} . \mathrm{m}^{-1}$ applied magnetic field. Methylene blue did not desorb from the magnetic biochar after the magnetic separation (100\% adsorbed before filtration, 100\% adsorbed after filtration). Similar results were obtained with or without the ultrasonication step before magnetic separation, which was used in the experiments in section III.1. Finally, no magnetic biochar particles were detected after the magnetic separation step, with or without adsorbed methylene blue (100\% particles retained by the magnetic filter). These results prove that the complete adsorption/magnetic separation procedure is very stable and allow to consider the system as an efficient tool for the treatment of polluted water.

\section{Conclusion}

In conclusion, magnetic biochar obtained from biorefinery co-products (humins) can be used for hydrophilic organic pollutant adsorption in a depollution system. In the particular case of methylene blue removal, electrostatic attraction between oppositely charged methylene blue and magnetic biochar was believed to be the dominant interaction governing adsorption at environmental $\mathrm{pH}$ values, whereas hydrogen bonds and $\pi-\pi$ stacking could be involved at low $\mathrm{pH}$ values. The maximum adsorption capacity of the humins-based magnetic biochar with respect to methylene blue molecules $\left(10.7 \mathrm{mg} \cdot \mathrm{g}^{-1}\right)$ was consistent with the range of values from the literature $\left(2.1-174.3 \mathrm{mg} \cdot \mathrm{g}^{-1}\right)$. The synthesis of magnetic biochar is easy to perform and of economic interest. 
Similarly, the magnetic separation of biochar particles is effective, efficient and does not interfere with the pollutant adsorption. Nevertheless, some further investigations are required, particularly regarding the magnetic separation device which was designed at the laboratory scale. Future studies will investigate the transposition of this technology to real-scale conditions.

\section{Declarations}

\section{Funding}

This work has been supported by the French government, through the UCA ${ }^{\mathrm{JEDI}}$ Investments in the Future project managed by the National Research Agency (ANR) with the reference number ANR15-IDEX-01. The scanning electron microscope of the Centre Commun de Microscopie Appliquée (CCMA) was funded by the Région Sud/Provence-Alpes-Côte d'Azur and the Conseil Départemental des Alpes Maritimes.

\section{Conflicts of interest/Competing interests}

Not applicable.

\section{Availability of data and material}

The authors confirm that the data supporting the findings of this study are available within the article itself.

\section{Acknowledgement}

This is a post-peer-review, pre-copyedit version of an article published in "Waste and Biomass Valorization". The final authenticated version is available online at:

\section{http://link.springer.com/article/10.1007/s12649-021-01481-3.}

\section{References}

[1] Sun, L., Wan, S., Luo, W.: Biochars prepared from anaerobic digestion residue, palm bark, and eucalyptus for adsorption of cationic methylene blue dye: characterization, equilibrium, and kinetic studies. Bioresour. Technol. 140, 406-413 (2013)

[2] Yang, G., Wu, L., Xian, Q., Shen, F., Wu, J., Zhang, Y.: Removal of congo red and methylene blue from aqueous solutions by vermicompost-derived biochars. PloS One 11(5), e0154562 (2016) 
[3] Hoslett, J., Ghazal, H., Ahmad, D., Jouhara, H.: Removal of copper ions from aqueous solution using low temperature biochar derived from the pyrolysis of municipal solid waste. Sci. Total Environ. 673, 777-789 (2019)

[4] Zhao, J., Shen, X. J., Domene, X., Alcañiz, J. M., Liao, X., Palet, C.: Comparison of biochars derived from different types of feedstock and their potential for heavy metal removal in multiplemetal solutions. Sci. Rep. 9(1), 1-12 (2019)

[5] Ferrentino, R., Ceccato, R., Marchetti, V., Andreottola, G., Fiori, L.: Sewage sludge hydrochar: an option for removal of methylene blue from wastewater. Appl. Sci. 10(10), 3445 (2020)

[6] Saha, N., Volpe, M., Fiori, L., Volpe, R., Messineo, A., Reza, M. T.: Cationic Dye Adsorption on Hydrochars of Winery and Citrus Juice Industries Residues: Performance, Mechanism, and Thermodynamics. Energies 13(18), 4686 (2020)

[7] Kearns, J. P., Wellborn, L. S., Summers, R. S., Knappe, D. R.: U. 2, 4-D adsorption to biochars: Effect of preparation conditions on equilibrium adsorption capacity and comparison with commercial activated carbon literature data. Water Res. 62, 20-28 (2014)

[8] Del Bubba, M., Anichini, B., Bakari, Z., Bruzzoniti, M. C., Camisa, R., Caprini, C., Checchini, L., Fibbi, D., El Ghadraoui, A., Liguori, F., Orlandini, S.: Physicochemical properties and sorption capacities of sawdust-based biochars and commercial activated carbons towards ethoxylated alkylphenols and their phenolic metabolites in effluent wastewater from a textile district. Sci. Total Environ. 708, 135217 (2020)

[9] Xu, X., Schierz, A., Xu, N., Cao, X.: Comparison of the characteristics and mechanisms of Hg (II) sorption by biochars and activated carbon. J. Colloid Interface Sci. 463, 55-60 (2016)

[10] Essandoh, M., Wolgemuth, D., Charles, U.P. Jr, Mohan, D., Mlsna, T.: Adsorption of metribuzin from aqueous solution using magnetic and nonmagnetic sustainable low-cost biochar adsorbents. Environ. Sci. Pollut. Res. 24, 4577-4590 (2017)

[11] Zhang, L., Guo, J., Huang X.,Wang, W., Sun, P., Li, Y.,Han, J.: Functionalized biocharsupported magnetic $\mathrm{MnFe}_{2} \mathrm{O}_{4}$ nanocomposite for the removal of $\mathrm{Pb}$ (II) and $\mathrm{Cd}(\mathrm{II})$. $\mathrm{RSC} \mathrm{Adv} .9$, 365-376 (2019)

[12] Zhang, S.J., Ji, Y.L., Dang, J., Zhao, J., Chen, S.: Magnetic apple pomace biochar: Simple preparation, characterization, and application for enriching $\mathrm{Ag}(\mathrm{I})$ in effluents. Sci. Total Environ. $668,115-123$ (2019)

[13] Yi, Y.Q., Tu, G.Q., Zhao, D.Y., Tsang, P.E., Fang, Z.Q: Biomass waste components significantly influence the removal of $\mathrm{Cr}(\mathrm{VI})$ using magnetic biochar derived from four types of feedstocks and steel pickling waste liquor. Chem. Eng. J. 360, 212-220 (2019)

[14] Yi, Y.Q., Huang, Z., Lu, B., Xian, J., Tsang, P.E., Cheng, W., Fang, J., Fang, Z.Q.: Magnetic biochar for environmental remediation: A review, Bioresource Technol. 298, 122468 (2020) 
[15] Yao, X., Ji, L., Guo, J., Ge, S., Lu, W., Cai, L., Wang, Y., Song, W., Zhang, H.: Magnetic activated biochar nanocomposites derived from wakame and its application in methylene blue adsorption, Bioresource Technol. 302, 122842 (2020)

[16] Thines, K.R., Abdullah, E.C., Mubarak, N.M., Ruthiraan, M.: Synthesis of magnetic biochar from agricultural waste biomass to enhancing route for waste water and polymer application: A review, Renew. Sust. Energ. Rev. 67, 257-276 (2017)

[17] Altıntıg, E., Altundag, H., Tuzen, M., Sarı, A.: Effective removal of methylene blue from aqueous solutions using magnetic loaded activated carbon as novel adsorbent, Chem. Eng. Res. Des. 122, 151-163 (2017)

[18] Altintig, E., Onaran, M., Sarı, A., Altundag, H., Tuzen, M.: Preparation, characterization and evaluation of bio-based magnetic activated carbon for effective adsorption of malachite green from aqueous solution. Mater. Chem. Phys. 220, 313-321 (2018)

[19] Li, X., Wang, C., Zhang, J., Liu, J., Liu, B., Chen, G.: Preparation and application of magnetic biochar in water treatment: A critical review, Sci. Total Environ. 711, 134847 (2020)

[20] Shang, J., Pi, J., Zong, M., Wang, Y., Li, W., Liao, Q.: Chromium removal using magnetic biochar derived from herb-residue. J. Taiwan Inst. Chem. Eng. 68, 289-294 (2016)

[21] Dai, S.J., Zhao, Y.C., Niu, D.J., Li, Q., Chen, Y.: Preparation and re-activation of magnetic biochar by molten salt method: relevant performance for chlorine-containing pesticides abatement. J. Air Waste Manage. 6 (1), 58-70 (2019)

[22] Mojiri, A., Andasht Kazeroon, R., Gholami, A.: Cross-linked magnetic chitosan/ activated biochar for removal of emerging micropollutants from water: optimization by the artificial neural network. Water 11 (3), 551 (2019)

[23] Yap, M.W., Mubarak, N.M., Sahu, J.N., Abdullah, E.C.: Microwave induced synthesis of magnetic biochar from agricultural biomass for removal of lead and cadmium from wastewater. J. Ind. Eng. Chem. 45, 287-295 (2017)

[24] Ruthiraan, M., Abdullah, E. C., Mubarak, N. M., Noraini, M. N.: A promising route of magnetic based materials for removal of cadmium and methylene blue from waste water. $\mathrm{J}$. Environ. Chem. Eng. 5(2), 1447-1455 (2017)

[25] Sharma, P., Hussain, N., Borah, D.J., Das, M.R.: Kinetics and adsorption behavior of the methyl blue at the graphene oxide/reduced graphene oxide nanosheet-water interface: A comparative study. J. Chem. Eng. Data 58, 3477- 3488 (2013)

[26] Mallampati, R., Xuanjun, L., Adin, A., Valiyaveettil, S.: Fruit peels as efficient renewable adsorbents for removal of dissolved heavy metals and dyes from water. ACS Sustain. Chem. Eng. 3, 1117-1124 (2015) 
[27] Chen, Y., Cui, Z., Ding, H., Wan, Y., Tang, Z., Gao, J.: Cost-effective biochar produced from agricultural residues and its application for preparation of high performance form-stable phase change material via simple method. Int. J. Mol. Sci. 19(10), 3055 (2018)

[28] Banitalebi, G., Mosaddeghi, M. R., Shariatmadari, H.: Feasibility of agricultural residues and their biochars for plant growing media: Physical and hydraulic properties. Waste Manage. 87, 577589 (2019)

[29] Campos, P., Miller, A. Z., Knicker, H., Costa-Pereira, M. F., Merino, A., De la Rosa, J. M.: Chemical, physical and morphological properties of biochars produced from agricultural residues: Implications for their use as soil amendment. Waste Manage. 105, 256-267 (2020)

[30] Elkhalifa, S., AlNouss, A., Al-Ansari, T., Mackey, H. R., Parthasarathy, P., Mckay, G. Simulation of Food waste pyrolysis for the production of biochar: a qatar case study. Comput. Aided Chem. Eng. 46, 901-906 (2019)

[31] Xu, C., Zhao, J., Yang, W., He, L., Wei, W., Tan, X., Wang J., Lin, A.: Evaluation of biochar pyrolyzed from kitchen waste, corn straw, and peanut hulls on immobilization of $\mathrm{Pb}$ and $\mathrm{Cd}$ in contaminated soil. Environ. Poll. 261, 114133 (2020)

[32] Rodriguez, J. A., Lustosa Filho, J. F., Melo, L. C. A., de Assis, I. R., de Oliveira, T. S.. Influence of pyrolysis temperature and feedstock on the properties of biochars produced from agricultural and industrial wastes. J. Anal. Appl. Pyrol. 149, 104839 (2020)

[33] Shi, Y., Shan, R., Lu, L., Yuan, H., Jiang, H., Zhang, Y., Chen, Y.: High-efficiency removal of Cr (VI) by modified biochar derived from glue residue. J. Clean. Prod. 254, 119935 (2020)

[34] Filiciotto, L., Balu, A.M., Van der Waal, J.C., Luque, R.: Catalytic insights into the production of biomass-derived side products methyl levulinate, furfural and humins. Catal. Today 302, 2-15 (2018)

[35] Hoang, T.M.C., Lefferts, L., Seshan, K.: Valorization of Humin-Based Byproducts from Biomass Processing —A Route to Sustainable Hydrogen. ChemSusChem 6(9), 1651-1658 (2013)

[36] Mija, A., van der Waal, J.C., Pin, J.-M., Guigo, N., de Jong, E.: Humins as promising material for producing sustainable polyssacharide-derived building materials. Constr. Build. Mater. 139, 594-601 (2017)

[37] Tosi, P., van Klink, G.P., Celzard, A., Fierro, V., Vincent, L., de Jong, E., Mija, A.: AutoCrosslinked Rigid Foams Derived from Biorefinery Byproducts. ChemSusChem 11(16), 27972809 (2018)

[38] Tosi, P., van Klink, G.P., Hurel, C., Lomenech, C., Celzard, A., Fierro, V., Delgado-Sanchez, C.,Mija, A.: Investigating the properties of humins foams, the porous carbonaceous materials derived from biorefinery by-products. Appl. Mater. Today 20, 100622 (2020)

[39] Karunanayake, A.G., Bombuwala Dewage, N., Todd, O.A., Essandoh, M., Anderson, R., Mlsna, T., Mlsna, D.: Salicylic acid and 4-nitroaniline removal from water using magnetic biochar: 
an environmental and analytical experiment for the undergraduate laboratory. J. Chem. Educ. 93(11), 1935-1938 (2016)

[40] Rosensweig, R. E.: Ferrohydrodynamics, Cambridge University Press, Cambridge (1985)

[41] Lagergren, S.Y.: Zur Theorie der sogenannten Adsorption gelöster Stoffe. Kungl. Svenska Vetenskapsakad Handl. 24, 1-39 (1898)

[42] Blanchard, G., Maunaye, M., Martin, G.: Removal of heavy metals from waters by means of natural zeolites. Water Res. 18(12), 1501-1507 (1984).

[43] Ho, Y.S., McKay, G.: Pseudo-second order model for sorption processes. Process Biochem. 34(5), 451-465 (1999)

[44] Lin, J., Wang, L.: Comparison between linear and non-linear forms of pseudo-first-order and pseudo-second-order adsorption kinetic models for the removal of methylene blue by activated carbon. Front. Environ. Sci. Eng. China 3(3), 320-324 (2009)

[45] Simonin, J.P.: On the comparison of pseudo-first order and pseudo-second order rate laws in the modeling of adsorption kinetics. Chem. Eng. J. 300, 254-263 (2016)

[46] Langmuir, I.: The constitution and fundamental properties of solids and liquids. Part I. Solids. J. Am. Chem. Soc. 38, 2221-2295 (1916)

[47] Freundlich, H.: Über die Adsorption in Lösungen. Z. Phys. Chem. 57(1), 385-470 (1907)

[48] Raman, A., Kuban, B., Razvan, A.: The application of infrared spectroscopy to the study of atmospheric rust systems-I. Standard spectra and illustrative applications to identify rust phases in natural atmospheric corrosion products. Corros. Sci. 32(12), 1295-1306 (1991)

[49] Cornell, R. M., Schwertmann, U.: The iron oxides: structure, properties, reactions, occurrences and uses. John Wiley \& Sons, Weinheim (2003)

[50] Fuente, E., Menéndez, J.A., Diez, M.A., Suarez, D., Montes-Morán, M.A.: Infrared spectroscopy of carbon materials: a quantum chemical study of model compounds. J. Phys. Chem. B 107(26), 6350-6359 (2003)

[51] Grosvenor, A.P., Kobe, B.A., Biesinger, M.C., McIntyre, N.S.: Investigation of multiplet splitting of Fe 2p XPS spectra and bonding in iron compounds. Surf. Interface Anal. 36(12), 15641574 (2004)

[52] Kosmulski, M.: The pH-dependent surface charging and points of zero charge: V. Update. J. Colloid Interface Sci. 353(1), 1-15 (2011)

[53] Ji, L., Zhou, L., Bai, X., Shao, Y., Zhao, G., Qu, Y., Li, Y.: Facile synthesis of multiwall carbon nanotubes/iron oxides for removal of tetrabromobisphenol A and $\mathrm{Pb}$ (II). J. Mater. Chem. 22(31), 15853-15862 (2012) 
[54] Gupta, V.K., Agarwal, S., Saleh, T.A.: Chromium removal by combining the magnetic properties of iron oxide with adsorption properties of carbon nanotubes. Water Res. 45(6), 2207$2212(2011)$

[55] Qiu, Y., Zheng, Z., Zhou, Z., Sheng, G.D.: Effectiveness and mechanisms of dye adsorption on a straw-based biochar. Bioresour. Technol. 100(21), 5348-5351 (2009)

[56] Villaescusa, I., Fiol, N., Poch, J., Bianchi, A., Bazzicalupi, C.: Mechanism of paracetamol removal by vegetable wastes: the contribution of $\pi-\pi$ interactions, hydrogen bonding and hydrophobic effect. Desalination 270(1-3), 135-142 (2011)

[57] Tan, X., Liu, Y., Zeng, G., Wang, X., Hu, X., Gu, Y., Yang, Z.: Application of biochar for the removal of pollutants from aqueous solutions. Chemosphere 125, 70-85 (2015)

[58] Fan, S., Tang, J., Wang, Y., Li, H., Zhang, H., Tang, J., Wang, Z., Li, X.: Biochar prepared from co-pyrolysis of municipal sewage sludge and tea waste for the adsorption of methylene blue from aqueous solutions: kinetics, isotherm, thermodynamic and mechanism. J. Mol. Liq. 220, 432$441(2016)$

[59] Güzel, F., Sayğılı, H., Sayğılı, G. A., Koyuncu, F., Yılmaz, C.: Optimal oxidation with nitric acid of biochar derived from pyrolysis of weeds and its application in removal of hazardous dye methylene blue from aqueous solution. J. Clean. Prod. 144, 260-265 (2017)

[60] Li, G., Zhu, W., Zhang, C., Zhang, S., Liu, L., Zhu, L., Zhao, W.: Effect of a magnetic field on the adsorptive removal of methylene blue onto wheat straw biochar. Bioresour. Technol. 206, 16-22 (2016)

[61] Shi, L., Zhang, G., Wei, D., Yan, T., Xue, X., Shi, S., Wei, Q.: Preparation and utilization of anaerobic granular sludge-based biochar for the adsorption of methylene blue from aqueous solutions. J. Mol. Liq. 198, 334-340 (2014)

[62] Zhang, M., Gao, B.: Removal of arsenic, methylene blue, and phosphate by biochar/AlOOH nanocomposite. Chem. Eng. J. 226, 286-292 (2013)

[63] Magnet, C., Kuzhir, P., Bossis, G., Meunier, A., Nave, S., Zubarev, A., Lomenech, C., Bashtovoi, V.: Behavior of nanoparticles clouds around a magnetized microsphere under magnetic and flow fields. Phys. Rev. E 89, 032310 (2014) 